\title{
AVANCES EN TECNOLOGÍA ARQUEOMÉTRICA PARA EL ESTUDIO DE CERÁMICAS ARQUEOLÓGICAS DEL ÁMBITO CIRCUMPUNEÑO
}

\author{
ADVANCES IN ARCHAEOMETRIC TECHNOLOGY FOR THE STUDY OF \\ ARCHAEOLOGICAL CERAMICS FROM THE CIRCUMPUNEÑO AREA
}

\author{
Verónica J. Acevedo ${ }^{1}$, Laura Staropoli ${ }^{2}$, Camila Riera Soto $^{3}$, Daiana Soto ${ }^{4}$, Valeria Herrera ${ }^{5}$ y Leonardo Rossi ${ }^{6}$
}

Recibido 19 octubre 2020. Aceptado 30 noviembre 2020

\begin{abstract}
Resumen: En los últimos años, la aplicación de los estudios arqueométricos se ha incrementado notablemente. Por un lado, porque se ha logrado expandir un campo interdisciplinario que ha permitido la capacitación de los profesionales. Por el otro, porque se han logrado desarrollar espacios de trabajo con acceso al uso de diferentes técnicas analíticas, así como el diálogo e intercambio en el análisis de los resultados entre especialistas.

En cuanto al estudio de materiales cerámicos arqueológicos, los avances en el desarrollo de las técnicas y la tecnología vinculada al trabajo arqueométrico ha facilitado la revisión de resultados y datos que fueran obtenidos oportunamente durante las investigaciones, con el fin de continuar explorando problemáticas arqueológicas y resolver cuestiones pendientes relacionadas con procesos de producción y circulación de materiales cerámicos, prácticas sociales de intercambio, interacción e integración y sus rituales asociados, entre otros.

Este trabajo tiene como objetivo mostrar la aplicación de nuevas tecnologías y metodologías adaptadas a materiales cerámicos para evaluar su potencial afín al alcance de la información obtenida y revisar e incorporar nuevos datos vinculados con el estudio de la procedencia de materias primas, caracterización de pastas y técnicas de manufactura usadas por los alfareros andinos.

Para ello, se presentan dos casos de estudio de cerámicas arqueológicas de la Quebrada de Humahuaca, provincia de Jujuy (Argentina), a partir de análisis realizados con petrografía-QEMSCAN, Raman-IFT-IR, microscopio UV-IR y microestratrigrafías de pigmentos. Los resultados obtenidos han ofrecido información adicional y específica para interpretar las interacciones dentro y fuera del espacio de la Quebrada de Humahuaca en diferentes momentos cronológicos del pasado prehispánico, dando cuenta del uso del espacio circumpuneño por las comunidades que lo habitaron.

Palabras clave: estudios arqueométricos, cerámica arqueológica, espacios interdisciplinarios, interacciones circumpuneñas.
\end{abstract}

\begin{abstract}
In recent years, the application of archeometric studies has increased notably. On the one hand, because it has managed to expand an interdisciplinary field that has allowed the training of professionals. On the other hand, because work spaces have been developed with access to the use of different analytical techniques, as well as dialogue and exchange in the analysis of the results between specialists.

Regarding the study of archaeological ceramic materials, advances in the development of techniques and technology related to archaeological work has facilitated the review of results and data that were obtained in a timely manner during the investigations, in order to continue exploring archaeological problems and solve pending issues related to processes of production and circulation of ceramic materials, social practices of exchange, interaction and integration and their associated rituals, among others.

This work aims to present the application of new technologies and methodologies adapted to ceramic materials to evaluate their potential related to the scope of the information obtained and to review and incorporate new data related to the study of the origin of raw materials, characterization of pastes and techniques of manufacturing used by Andean potters.

For this, two case studies of archaeological ceramics from the Quebrada de Humahuaca, Jujuy province (Argentina), are presented, based on analyzes carried out with petrography-QEMSCAN, Raman-IFT-IR, UV-IR microscope and pigment microstratrigraphy. The results obtained have offered additional and specific information to interpret the interactions inside and outside the space of the Quebrada de Humahuaca in different chronological moments of the pre-Hispanic past, giving an account of the use of the circumpuneño space by the communities that inhabited it.
\end{abstract}

Keywords: archeometric studies, archaeological ceramics, interdisciplinary spaces, circumpunean interactions.

1 Proyecto ArqueoLab-UBA, Instituto de Arqueología, Facultad de Filosofía y Letras, Universidad de Buenos Aires. veroacevedo71@ gmail.com

2 Proyecto ArqueoLab-UBA, Instituto de Arqueología, Facultad de Filosofía y Letras, Universidad de Buenos Aires. laustaropoli@ yahoo.com.ar

3 Programa Magister en Antropología, Instituto de Investigaciones Arqueológicas y Museo de la Universidad Católica del Norte, San Pedro de Atacama, Chile. cami.riera.soto@gmail.com
4 Proyecto ArqueoLab-UBA, Instituto de Arqueología, Facultad de Filosofía y Letras, Universidad de Buenos Aires. daiana.m.soto@ gmail.com

5 Proyecto ArqueoLab-UBA, Instituto de Arqueología, Facultad de Filosofía y Letras, Universidad de Buenos Aires. valenh1971@gmail. com

6 Asesor de Proyecto ArqueoLab-UBA, Instituto de Arqueología, Facultad de Filosofía y Letras, Universidad de Buenos Aires. lerossi@ sol-analiticas.com 


\section{Introducción}

La arqueometría constituye un campo disciplinar metodológico que comprende la aplicación de diferentes técnicas analíticas especializadas para caracterizar y estudiar materiales culturales de diversos orígenes y contexto (Chaupoulie, Sepúlveda, del Solar Velarde \& Wright, 2018; Guirao, 2015). Los métodos y técnicas son variables y sus usos están subordinados a las problemáticas de investigación desarrolladas por especialistas de diferentes disciplinas como arqueólogos, conservadores, restauradores e historiadores del arte, entre otros (Del Solar Velarde, Cantin \& Chaupoulie, 2018). La propuesta de trabajo utilizando una estrategia analítica tipo para el estudio del patrimonio cultural es poco pragmática, ya que cada objeto y/o material, así como las restricciones de acceso a cada objeto u obra y las problemáticas de investigación tienen múltiples facetas (Del Solar Velarde et al., 2018).

En estos últimos años, el impulso y el desarrollo de nuevas tecnologías analíticas han logrado la implementación y surgimiento de instrumentos de mayor resolución, sensibilidad y versatilidad, ya sean de mesada y/o portátiles. Estos equipos permiten una aproximación in situ y no destructiva a los vestigios, no sólo en los sitios arqueológicos, sino también en los depósitos de museos, instituciones públicas y laboratorios. Asimismo, contribuyen al desarrollo de los estudios de materiales arqueológicos para la obtención de datos cada vez más fiables (Acevedo, 2019; Acevedo et al., 2013).

Esta accesibilidad a los instrumentos ha estimulado la conformación de espacios de investigación, reflexión y diálogo interdisciplinario, donde los profesionales pueden realizar sus investigaciones arqueométricas de manera integral. A su vez, en estos espacios es posible preservar y resguardar materiales de suma importancia (Acevedo, 2019).

Sin embargo, aún hoy queda mucho por hacer al respecto, ya que es necesario aunar esfuerzos colectivos y asumir el compromiso de parte de todas las instituciones públicas y privadas para construir y formalizar dichos espacios de investigación, así como de resguardo del patrimonio cultural. Esto requiere de una gestión tanto política, económica como social para que estos espacios puedan desarrollarse y funcionar.

En este sentido, en Latinoamérica los expertos están uniendo esfuerzos para la conformación de una red de laboratorios especializados en arqueometría de carácter interdisciplinar, mediante la vinculación por convenios, con el fin de facilitar el acceso a la variabilidad de instrumentos en la práctica arqueométrica, así como para la discusión académica (Acevedo, 2019). La introducción de nuevos conceptos, grupos de interés y espacios asociados al estudio del patrimonio cultural implican un desafío en las formas de pensar y practicar la arqueología. De la misma manera, implica una reflexión sobre el rol de la disciplina en la sociedad como una construcción social que la vincula a las personas y no primariamente a las cosas, como lo hace el enfoque tradicional (Acevedo et al., 2020; Bonin, 2013; Endere, Chaparro \& Mariano, 2013).

En este contexto de reflexión y como un desafío a los cambios sociales, tecnológicos y científicos, surge el Proyecto ArqueoLabUBA, dentro del cual se enmarca este trabajo. Dicho proyecto es una iniciativa desarrollada por un grupo de investigadores formados en arqueología, antropología, conservación, historia del arte, química y especialistas en patrimonio de la Universidad de Buenos Aires. Todos ellos profesionales capacitados en el campo disciplinar de la arqueometría. El ArqueoLab-UBA se define como un laboratorio especializado en análisis e investigaciones arqueométricas, tecnológicas y virtuales para su estudio, conservación y puesta en valor del patrimonio cultural. El objetivo principal es investigar, conservar y difundir el conocimiento referente a los distintos aspectos de los bienes patrimoniales (tangibles, intangibles y virtuales) (Acevedo et al., 2020).

Comúnmente, un laboratorio es concebido como un espacio que se encuentra equipado con los medios necesarios para llevar a cabo investigaciones de carácter científico. Sin embargo, un laboratorio de estudio en bienes culturales conlleva otras características. Nuestro concepto de laboratorio plantea un nuevo significado, es entendido como un lugar de análisis donde se generan y se contrastan hipótesis acerca de la historia de vida de los bienes culturales y su conservación. Dichos bienes son pensados como medios materiales de información para difundir al público en general y como parte de nuestra memoria colectiva como sociedad (Acevedo, Staropoli, Herrera, Ciarlo \& Landa, 2018a, 2018b; Acevedo et al., 2020).

El objetivo del laboratorio es contribuir al desarrollo de las investigaciones arqueométricas a partir del trabajo interdisciplinario, el cual comprende diversas aproximaciones científicas. El propósito es generar conocimiento sobre el pasado humano, utilizando como medios de investigación y difusión el enfoque del Pensamiento Visible y la Ciencia Participativa, prácticas que conjugan nuestros objetivos científicos con los intereses de la comunidad (Acevedo et al., 2018a, 2018b; Acevedo et al., 2020).

Por otra parte, el conjunto de técnicas arqueométricas puede ser aplicado de dos formas diferentes. Por un lado, ciertas técnicas requieren de expertos y profesionales provenientes de las ciencias exactas y naturales, las ciencias de la tierra y la informática, entre otros especialistas, los cuales trabajan junto a los arqueólogos, conservadores, historiadores del arte, etc. Por el otro lado, existen técnicas o dispositivos que sólo requieren de la capacitación de los científicos sociales para diagnosticar, analizar y obtener resultados in situ. En ambos casos, la interacción entre expertos debe ser articulada y complementaria para generar un conocimiento colaborativo y subordinado a las problemáticas de la investigación arqueológica o patrimonial.

Caracterización y procedencia de materiales cerámicos arqueológicos mediante la aplicación de técnicas arqueométricas

En la arqueometría aplicada al estudio de materiales cerámicos no existe una sistematización sobre el uso específico o general de cierto tipo de técnicas. En este caso, un investigador debe ser ecléctico y abierto a dominar la variabilidad de posibilidades para confrontar sus resultados. Por un lado, debe especializarse y comprender la técnica a utilizar y no meramente ser un receptor del resultado comunicado por los técnicos, ya que es importante el trabajo interdisciplinario para construir el dato y relacionarlo al comportamiento humano que se está estudiando. Por otro lado, es importante conocer el abanico de técnicas disponibles, ya que en general, los espacios donde se desarrolla la investigación arqueológica no cuentan con todas las posibilidades y recursos.

En los últimos tiempos, como consecuencia de los avances tecnológicos, parte del instrumental de diagnóstico y análisis, especialmente utilizado para el estudio de cerámicas arqueológicas, se ha vuelto versátil y accesible, facilitando la tarea 
de los especialistas. Entre algunos de ellos, podemos mencionar los microscopios USB de alta definición con emisiones ópticas diferenciales y los instrumentos de caracterización elemental o composicional como espectroscopía Raman, fluorescencia de rayos X (FRX), espectroscopía infrarroja (IR). Estos últimos han evolucionado a formas portátiles y de mesada, permitiendo poner al alcance herramientas novedosas y selectivas, que permiten obtener nuevos datos y completarlos con los obtenidos mediante el uso de otras técnicas. Asimismo, permite asistir a la solución de interrogantes que hasta el momento no han tenido una respuesta satisfactoria (Acevedo, 2019).

En la actualidad, el estudio de colecciones de piezas completas de colección que se encuentran en museos, reservas o depósitos de instituciones dedicadas a su protección, es de gran interés para la contextualización del registro arqueológico y para sumar información a la misma colección. Sin embargo, la recuperación de datos a través de técnicas arqueométricas en estos contextos resulta compleja, ya que son limitadas las posibilidades de trasladar los objetos para estudiarlos en laboratorios especializados (Acevedo et al., 2013). Es así que, la sistematización del relevamiento, análisis arqueométrico y toma de micromuestras de las cerámicas de colección in situ puede realizarse a través de un protocolo sistematizado para el registro de los datos. Para ello, es preciso organizar los diversos niveles de análisis: macroscópicos, submacroscópicos, microscópicos y físico-químicos. Dichas tareas se vienen realizando desde hace un tiempo considerando el uso de técnicas no destructivas para la preservación de los materiales que estudiamos (Acevedo et al., 2013; Herrera \& Acevedo, 2019). Se ha diseñado, en particular para estos casos, un plan de trabajo in situ que comprende la toma de muestras y posterior traslado al laboratorio, el uso de nuevas tecnologías y el instrumental físico-químico de mesada, la obtención de datos por medio de técnicas de acceso expedito y luego el uso de un conjunto de técnicas complementarias aplicadas por expertos de otras disciplinas.

El análisis de un conjunto de materiales cerámicos a través de técnicas arqueométricas debe tomar en cuenta las diferentes etapas de la cadena operativa: fuentes y explotación de materias primas, técnicas de elaboración y cocción y los ciclos de distribución y utilización. Los instrumentos empleados en la caracterización arqueométrica de estos materiales permiten acceder a sus características químicas y físicas y conocer el proceso de producción. Según Druc $(2005,2014)$, la caracterización de cerámicas comprende la identificación de sus componentes y está fundamentada en las diferencias químicas, por ejemplo, entre distintas fuentes de materias primas. Esta diferencia puede ser identificada por métodos analíticos y ser reconocida en la composición de materiales cerámicos, pero requieren de los estudios etnográficos, etnoarqueológicos y experimentales que son fundamentales para la interpretación de los resultados arqueométricos.

\section{Casos de estudio e interacciones en el ámbito Circumpuneño}

El objetivo de este trabajo es evaluar el potencial vinculado al alcance de la información obtenida y revisar e incorporar nuevos datos a partir de la aplicación de diferentes técnicas arqueométricas para el análisis de dos casos de estudio de cerámicas arqueológicas de la Quebrada de Humahuaca, provincia de Jujuy (Argentina) con el fin de dilucidar el uso simbólico del espacio circumpuneño.
Los antecedentes sobre la temática muestran un consenso en relación con la circulación de bienes, individuos $\mathrm{y} / \mathrm{o}$ caravanas en los Andes circumpuneños (SO de Bolivia y NO de Argentina, región II de Chile) desde épocas tempranas (Figura 1). Esta subárea se diferencia del resto del área de los Andes Centro-Sur, por su mayor aridez y por los marcados contrastes en la productividad, caracterizada por bolsones relativamente fértiles separados por franjas improductivas (desiertos, cumbres montañosas). Estas características ambientales se han traducido en una distribución muy desigual de la población a lo largo de la historia. Los lugares favorables para el asentamiento humano corresponden a tres tipos principales con potencial productivo decreciente: valles mesotérmicos del flanco oriental como la Quebrada de Humahuaca y el Valle Calchaquí, cuencas altiplánicas como el norte de Lípez y Doncellas-Miraflores y valles y oasis del flanco occidental como el Loa superior y los oasis de Atacama (Nielsen, 2006a, 2010). Otros autores, refieren a este ámbito como altiplano meridional o subárea circumpuneña, cuyas características representan una suerte de frontera ecológica, cultural, social y económica donde se observa múltiples variantes culturales de los distintos grupos que la habitaron y cuyas prácticas complementarias estaban destinadas a resolver las diferentes necesidades. Este modelo podría coincidir o diferir de los modelos difundidos para los Andes centrales (Aldunate \& Castro, 1981; Martínez, 1990).

La evidencia arqueológica de momentos prehispánicos muestra las diferentes vinculaciones culturales, sociales y/o político-económicas de la Quebrada de Humahuaca con las regiones aledañas, Puna, Altiplano boliviano y zona de yungas, que en conjunto conforman el marco regional de los Andes circumpuneños (Figura 1) (Aldunate \& Castro, 1981; Nielsen, 2010).

Cabe aclarar que los estudios de casos fueron realizados en dos etapas diferentes de investigación. En la primera de ellas, realizada hace unos años, se utilizó la espectroscopía Raman, combinada con difracción de rayos X (DRX) y microscopía de barrido electrónico y análisis químico (SEM-EDS), técnicas innovadoras para ese momento, cuyos resultados permitieron avanzar en la formulación de los problemas relacionados a la caracterización, circulación y uso/consumo de los materiales cerámicos analizados, dejando algunos interrogantes sin resolver (Acevedo, 2011, 2014; Acevedo et al., 2012; Freire et al., 2015; Marte, Acevedo \& Mastrangello et al., 2012). En una segunda etapa, desarrollada en la actualidad, se procedió a continuar con el trabajo, pero ampliando los resultados a partir de la aplicación de nuevas técnicas como petrografía QEMSCAN, microespectroscopía Raman-IFT-IR, microscopio UV-IR y microestratigrafías de pigmentos. En esta oportunidad, los resultados obtenidos han ofrecido información adicional y específica para interpretar las interacciones dentro y fuera del espacio de la Quebrada de Humahuaca en diferentes momentos cronológicos del pasado prehispánico (Acevedo, 2015; Acevedo, Riera Soto \& Staropoli, 2019; Riera Soto, Uribe, Menzies \& Barraza, 2018).

\section{Caso 1: circulación y ritualidad en el espacio circumpuneño en el inicio de las sociedades productoras de alimentos}

La interacción para los pueblos andinos que habitaron los Andes Centro-Sur, significó un modo de vida en el cual 


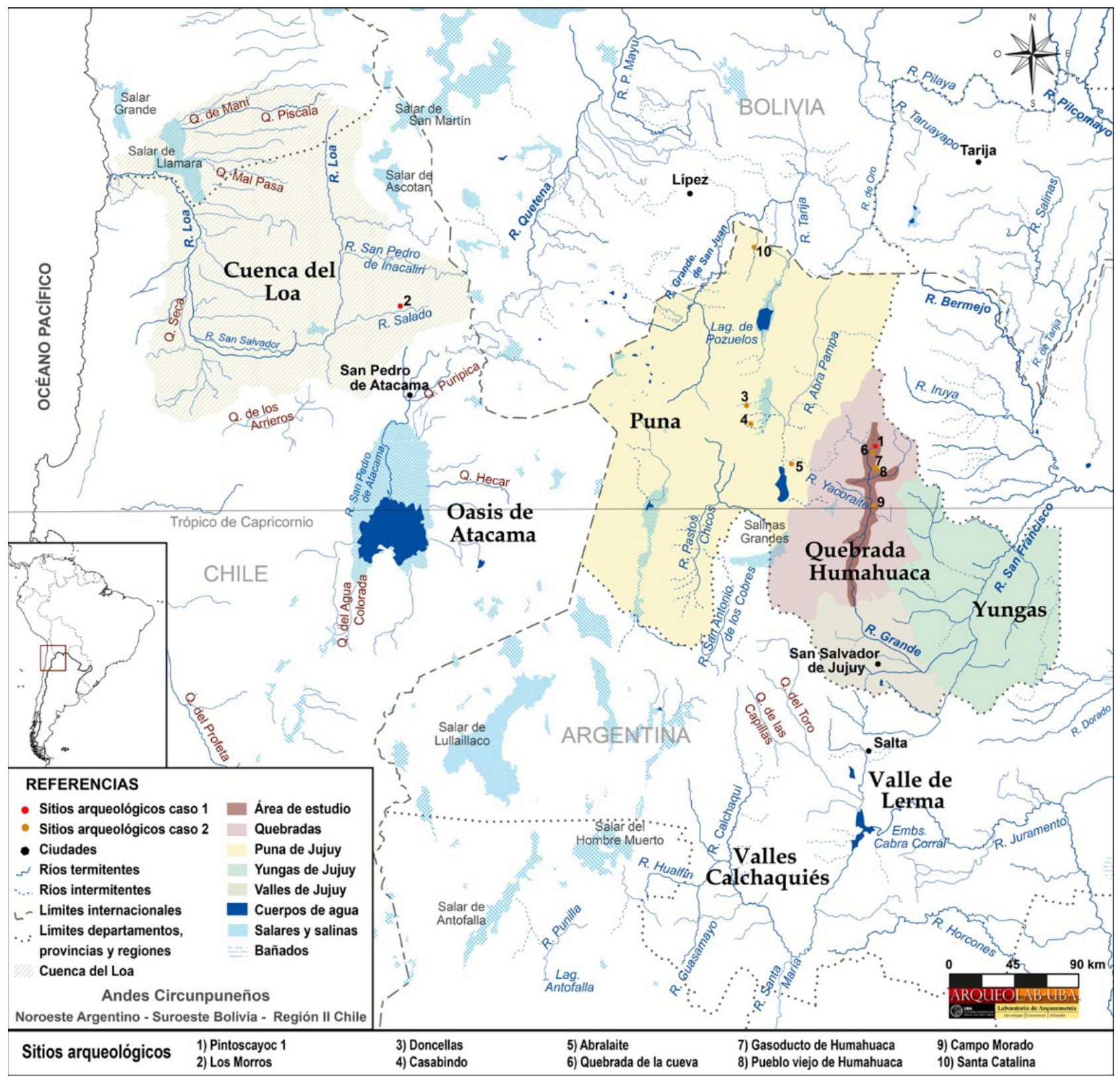

Figura 1. Mapa de la región de estudio con la localización de los Andes circumpuneños, la Quebrada de Humahuaca, las regiones aledañas y los sitios arqueológicos mencionados en el texto.

se vincularon las diferentes organizaciones sociales. Las comunidades del ámbito andino que poblaron la región de la Quebrada de Humahuaca, Noroeste Argentino (NOA) y del norte de Chile, transitaron los caminos del área circumpuneña desde momentos muy tempranos, compartiendo prácticas sociales de intercambio con dinámicas intra e interregionales formando una cadena de relaciones territoriales y rituales. La complementariedad de recursos entre poblaciones que se relacionaron en ese espacio social, simbólico y geográfico se ha visto reflejada en el registro arqueológico del área (Castro \& Tarragó, 1993; Tarragó, 2000; Nielsen, 1998; Olivera, 2001; entre otros). En ese contexto, la producción y circulación de bienes pudo ser un componente social importante para establecer la idiosincrasia particular de un grupo frente a otro dentro de un ámbito geográfico compartido.

Los pueblos andinos han conservado una relación sagrada con la naturaleza que los rodea, manteniendo desde el pasado prehispánico hasta el presente ritos y ceremonias propiciatorias de bienestar y de agradecimiento. Para ellos, el paisaje es una construcción cultural simbólicamente ritualizada que se proyecta en su materialidad religiosa y que les permite ser actores de un mundo sagrado (Acevedo, Espinosa, López \& Mancini 2009; Acevedo, 2014).

Los investigadores del área coinciden en que el modo de vida de pastoreo ya estaba instalado hacia el 1.000 a.C. (ca. 3.000 años A.P.). La información arqueológica disponible indica que, en los distintos lugares de los Andes Centro-Sur, este modo de vida se manifestó durante este lapso con marcadas variaciones locales 
y temporales. Asimismo, los cambios culturales implicaron la transformación sustancial de las formas de organización de la subsistencia, asentamiento, tecnología, estructuras y vínculos sociales intra e intergrupales, así como las formas de concebir su mundo (Castro \& Tarragó, 1993; Tarragó, 2000; Nielsen, 1998; Olivera, 2001).

El inicio de las sociedades productoras de alimentos, denominado como período Formativo en el NOA, refiere a sociedades que poseían un componente productivo, agrícola y/o pastoril, en su economía (Olivera, 2001). Sin embargo, las reflexiones actuales refieren a este momento como una etapa de diversidad cultural en relación a la subsistencia, con configuraciones sociales únicas y nuevas combinando actividades extractivas y productivas, exploración de ecozonas y desplazamientos estacionales, así como una variabilidad en la obtención de alimentos, uso del espacio, organización doméstica, social y ritualidad (Nielsen, 2017). Desde el punto de vista cronológico, la mayor parte de los asentamientos de ese momento se ubican entre los $c a$. 2.500 a 1.200 años A.P., fecha relacionada al inicio de las aldeas agropastoriles en la región, aunque otros investigadores ubican su inicio con anterioridad (Nielsen, 2017; Olivera, 2001). En este contexto de cambio en las prácticas económicas productivas, la introducción de nuevas tecnologías ha jugado un rol central en la definición del Formativo en el NOA (Leoni y Hernández Llozas, 2015). Es así como la Quebrada de Humahuaca fue habitada por diversos grupos que utilizaron este espacio como una conexión natural entre tierras altas y bajas, lo que fue un factor determinante en el sistema de circulación de recursos, objetos y conocimiento.

\section{Materiales y métodos de estudio del caso 1}

En las nacientes de la Quebrada, donde nace el Río Grande, entre las localidades de Azul Pampa e Iturbe, se encuentra la localidad arqueológica Pintoscayoc ${ }^{1}$, ubicada en los escalones altitudinales de quebradas altas, entre los 3.200 y $4.600 \mathrm{msnm}$ (Figura 1). Los sitios que la componen, importantes por su conexión directa hacia la Puna, las Yungas y la dinámica regional circumpuneña, fueron refugio de manifestaciones rupestres, rituales y/o ceremoniales desde el 10.000 A.P. y hasta tiempos poscoloniales (Hernández Llosas, 1991, 2006; Nielsen, 1998).

El primer caso de estudio refiere al análisis de materiales cerámicos encontrados en el contexto de la estructura $\mathrm{F}$ del sitio Pintoscayoc 1(Figura 1). Dicho contexto estaba compuesto por una fosa, correspondiente a una estructura de cavado intencional de origen humano, en la cual se encontró una camada de paja de $50 \mathrm{~cm}$ de diámetro, donde sobre ella se depositaron partes seleccionadas y articuladas del esqueleto postcraneal de un niño de seis u ocho años de edad, aunque con el faltante de gran parte de la porción superior del torso, siendo que algunos dientes acompañaban al conjunto (Hernández Llosas, 1998). En ese contexto y a modo de ocupar el espacio del cráneo, se encontró un puco $^{2}$ o escudilla de interior negro-pardo pulido con incrustaciones de mica, formando un motivo geométrico particular y único hasta el momento (Figura 2) (Acevedo, 2011, 2014; Hernández Llosas, 1998). El fechado contextual a los restos óseos humanos hallados dentro de la estructura fue realizado con la técnica de radiocarbono arrojando una fecha de $2.906 \pm 53$ años A.P. (GX-20443-G-AMS) (Hernández Llosas, 1998). Ese conjunto de restos fue tapado con morteros de piedra de gran tamaño, superpuestos unos sobre otros. Fuera del contexto sellado por los morteros y a la misma profundidad, se halló un caracol terrestre (Strophocheilus oblongus musculus), cuya presencia en el ambiente de ceja de selva es abundante, y que presentaba gran cantidad de pigmento rojo en su interior (Hernández Llosas, 1998), además de materiales cerámicos dispersos y diversos, objetos de esta investigación. A su vez, los morteros, que cubrían la fosa, contenían restos de una sustancia negra. Tanto el pigmento rojo del caracol como la sustancia negra sobre morteros, fueron analizados oportunamente mediante DRX y SEM-EDS, dando como resultado un rojo de óxido de hierro para el contenido de pigmento del caracol (hematita) y una mezcla pigmentaria de sal de potasio con manganeso para el negro de la superficie de los morteros (Acevedo, 2014).

El puco de cerámica de particularidades excepcionales, dado por su manufactura y diseño original, encontrado en este posible espacio ritual/ceremonial (Figura 2) (Acevedo, 2011, 2014), presenta una cronología de ca. 2.900 años A.P. momentos de inicio de las sociedades productoras de alimentos (Hernández Llosas, 1998).

En una etapa previa, hace ya unos años, a partir de los análisis de caracterización tecnológica y del estudio de los procesos de elaboración de este objeto, se pudieron conocer las singularidades del sistema técnico, que reveló un manejo tecnológico complejo por parte de los alfareros productores y del posible lugar de procedencia. Asimismo, la aplicación conjunta de diversos enfoques analíticos (microscopía óptica, SEM-EDS, rayos X (RX), Raman y petrografía cerámica), permitió conocer los procesos de producción del material estudiado y profundizar en el conocimiento de la importancia social del intercambio y la circulación de objetos en el ámbito circumpuneño (Figura 2) (Acevedo, 2014).
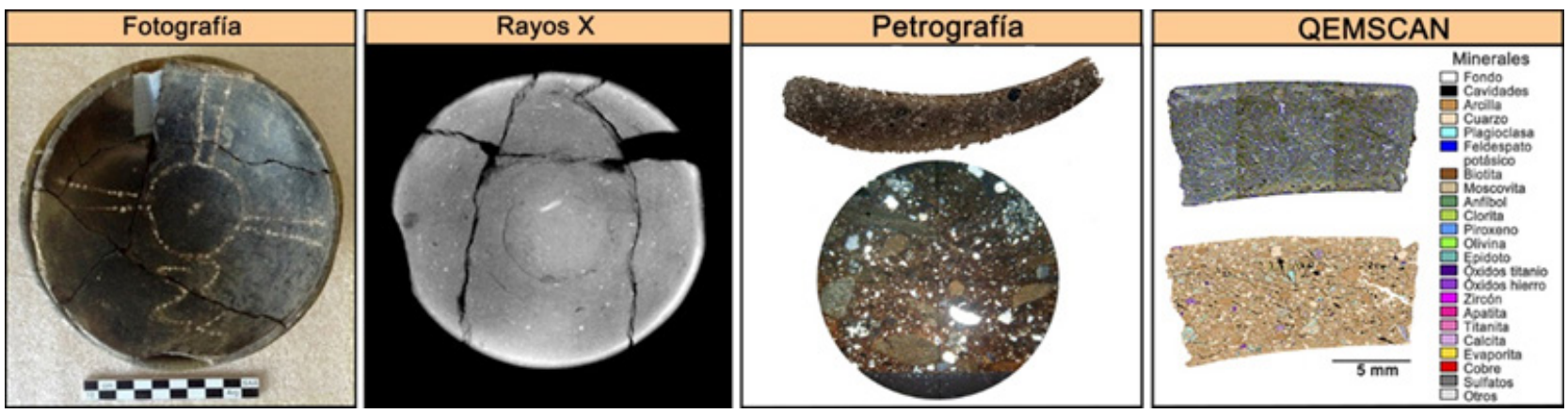

Figura 2. Puco con diseño único y las distintas técnicas analíticas aplicadas. 
Dicho estudio es ampliado en este trabajo, con la incorporación de otros fragmentos cerámicos hallados en el mismo contexto de excavación del sitio Pintoscayoc 1 (Figura 1), a los cuales se aplicó el análisis petrográfico en combinación con el uso de la técnica QEMSCAN. El uso de esta última técnica sumó patrones mineralógicos automatizados de cerámicas procedentes del ámbito circumpuneño de la región II de Chile, haciendo posible comparar la tecnología cerámica entre regiones y conocer datos sobre la procedencia de los materiales cerámicos (Acevedo, 2014; Acevedo et al., 2019; Riera Soto et al., 2018).

\section{Análisis de la pieza cerámica: puco}

El análisis tecnológico y arqueométrico sobre la pieza cerámica fue completa, integral y exhaustiva (Acevedo, 2011, 2014). A continuación, se presenta una síntesis de los resultados sobre este material cerámico.

La síntesis de los resultados realizados mediante diversos enfoques analíticos, (microscopía óptica, SEM-EDS, RX, microespectroscopía Raman, estudios de pastas y petrografía cerámica) para la caracterización y procedencia del objeto como de los patrones de elaboración de la pieza y de cocción, indicó que las diversas líneas de evidencia dan cuenta de un manejo tecnológico complejo por parte de quienes producían este tipo de objetos. La técnica de manufactura, la decoración particular y excepcional, el manejo de temperaturas y ambiente de cocción de la pieza, los datos contextuales, los datos de registro arqueológico de la región del Loa y los análisis realizados, apoyan la hipótesis acerca del origen alóctono a la Quebrada de Humahuaca. Los datos sobre la posible procedencia del norte de Chile, más específicamente con el grupo de estilo cerámico los Morros A de la región del Loa, se apoya en los estudios tecnológicos y petrográficos (para más especificaciones sobre los diferentes resultados mencionados, ver: Acevedo, 2011, 2014).

En relación a la caracterización y procedencia de la pieza estudiada, en lo que nos centramos aquí, el detalle del análisis petrográfico arrojó los siguientes datos:

- Grado de redondeamiento de los cuarzos importante (componente mayoritario de la pasta).

- Cantidad de cuarzos policristalinos de gran tamaño moderada.

- Presencia de líticos sedimentarios de tamaño mediano grueso abundante.

- Presencia de líticos ígneos de origen plutónico (granitoides).

La síntesis de resultados sumados a los estudios de petrografía cerámica permite pensar que el ambiente de procedencia de estos materiales es geomorfológicamente asimilable a una región de valles fluviales. Esto podría ser coincidente con las características del valle del lado chileno de la cordillera (probablemente el valle de Loa).

A partir del análisis de los procesos de elaboración de este objeto, se pudieron conocer las singularidades del sistema técnico y del posible lugar de procedencia, lo que permitió profundizar en el conocimiento de la importancia social del intercambio y la circulación de objetos en el ámbito de las comunidades andinas del pasado (Acevedo, 2014). Sin embargo, para completar y confirmar estos datos fue necesario comparar con muestras de cerámicas de varias zonas de la región II de Chile que integran el ámbito circumpuneño (Figura 1).

Nuevos estudios analíticos sobre materiales cerámicos contextuales

Para continuar con la investigación, se propuso articular los análisis petrográficos realizados al puco con los análisis petrográficos realizados a las muestras de fragmentos cerámicos del mismo contexto, para luego aplicar la técnica de análisis mineralógico automatizado QEMSCAN, a fin de obtener caracterizaciones cuantitativas, siendo una nueva alternativa tecnológica sensible, potente y poco usada en el ámbito arqueológico (Riera Soto et al., 2018).

El material cerámico fragmentario asociado al contexto de la estructura $\mathrm{F}$ presenta características muy disímiles entre sí. Se trata de una muestra acotada pero muy diversa, siendo los acabados de superficie lo que distingue a cada fragmento junto con los diferentes patrones de conformación de la pasta. Los análisis de pasta realizados con microscopía óptica sobre cortes frescos permitieron obtener una primera distinción, para así continuar con los análisis de petrografía cerámica sobre láminas delgadas y cortes frescos en tabletas de resina para aplicar la técnica QEMSCAN. Todos los fragmentos podrían corresponderse con piezas de tamaño pequeño como pucos, vasos chatos o dedales según Palma (1998).

En el análisis de tratamiento de superficie y de las pastas cerámicas se pudo reconocer que el fragmento 1 que corresponde al puco con diseño en mica, tiene un tratamiento de superficie alisado y engobe con inclusiones de láminas de micas en la mezcla de ambas caras, presenta un color negro-pardo desparejo por sectores, debido a los efectos de la atmósfera de cocción predominantemente reductora. La pasta es de aspecto compacto, textura fina, contiene inclusiones de tamaño heterogéneo y el núcleo de cocción presenta reducción completa. Además, se pueden observar grietas alargadas en varios sectores de la pasta, que corresponden al patrón de técnica de pinching o pellizcado según Rye (1981) (Acevedo, 2011, 2014) (Figuras 2, $3)$. Dichas características, sumadas a los datos tecnológicos, no indican analogía en relación a las características de cerámicas arqueológicas de la Quebrada de Humahuaca para el período en estudio (Acevedo, 2011, 2014).

A grandes rasgos, las pastas cerámicas de la Quebrada de Humahuaca presentan características de un ambiente metamórfico (por ejemplo, lutitas y/o pizarras) y otros derivados de los procesos presentes en la Formación Puncoviscana, que recorre longitudinalmente la región de la Quebrada de Humahuaca. Estas características hacen que la conformación de pastas de textura mediano-gruesa con inclusiones heterogéneas y de cocción predominantemente oxidante sea particular (Acevedo, 2011).

El fragmento 2 presenta como tratamiento de superficie un buen acabado de su engobe, de color anaranjado y con paredes finas. Además, presenta una pasta de textura fina y compacta con inclusiones de gran variabilidad de tamaño homogéneo y contiene gran cantidad de mica dorada (biotita) en la pasta. Su cocción es predominantemente oxidante y la técnica de manufactura de la pieza, posiblemente es el modelado drawing o levantado según Rye (1981) (Figura 3). Estas características son comparables con fragmentos escasos y ocasionales hallados en superficie en diferentes sitios del norte de la Quebrada de Humahuaca. Sin embargo, el patrón de las pastas no se correlaciona con las 


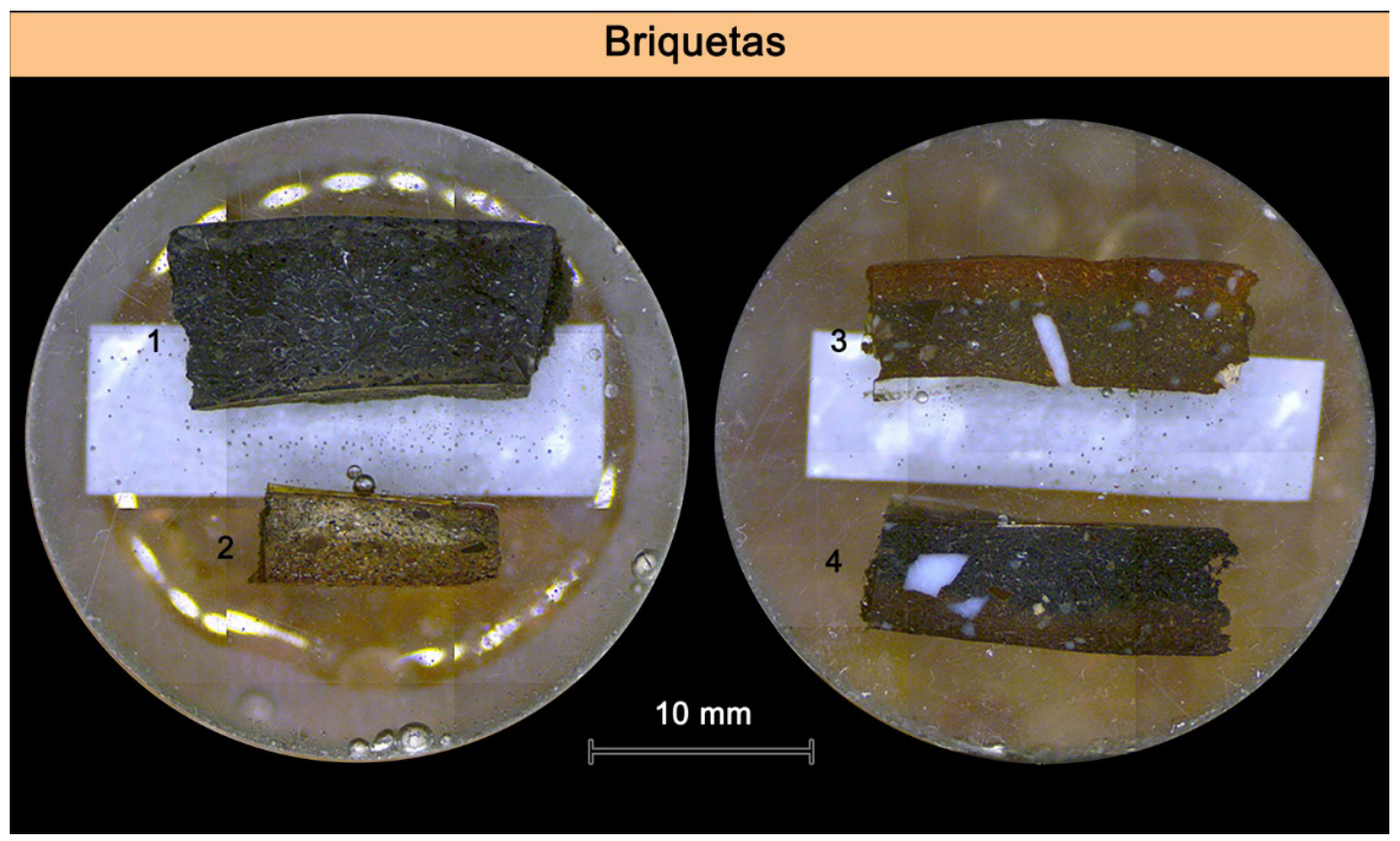

Figura 3. Muestras de los cortes frescos de los cuatro fragmentos del caso 1 que fueron incluidos en briquetas de resina para el análisis por la técnica QEMSCAN.

características de la cerámica de esa región para el período, como tampoco se puede relacionar con la tecnología del puco analizado (Acevedo, 2011).

El fragmento 3 posee una pasta de granulometría fina con inclusiones de cuarzo de tipo cristalino y otras posibles rocas metamórficas y sedimentarias de color blanco, ambas de tamaño mediano-grande, su superficie está alisada en ambas caras y el color del engobe es rojizo intenso. El núcleo de cocción es reductor con indicios de oxidación rápida por el aire según López (1999-2001), lo cual permite inferir una atmósfera de cocción diferente a la muestra 1 (puco) y al fragmento 2 (Figura 3). Además, presenta cavidades y/o poros circulares en todo el corte fresco observado y no se pudo distinguir la técnica de modelado. En comparación con las otras muestras de la región, el análisis preliminar de este fragmento parece indicar ser foráneo a la producción en Quebrada de Humahuaca.

El fragmento 4, el último seleccionado para ser analizado petrográficamente con microscopio polarizado y automatizado contiene inclusiones en cuarzo de color blanco y sus tamaños están poco seleccionados. Además, presenta alisado y engobe de color amarronado y el núcleo de cocción es mixto (reducciónoxidación) según López (1999-2001) (Figura 3). En este caso, tampoco se pudo distinguir la técnica de modelado y el patrón tecnológico no se corresponde con la región de la Quebrada de Humahuaca. Los fragmentos 3 y 4 presentan patrones que pueden adjudicarse a una misma tradición tecnológica.

Análisis petrográfico y QEMSCAN (Quantitative Evaluation of Minerals by Scanning Electron Microscopy)

Los cuatro fragmentos de cerámicas mencionados anteriormente fueron sometidos a distintas escalas de análisis. En primer lugar, se registraron todas las características macroscópicas mediante fotografías, microfotografías e imágenes RX, luego se extrajo una fracción de cada uno para la tableta residual de los cortes delgados para el análisis petrográfico, de los cuales la mitad fue analizada con microscopio de luz polarizada y la otra mitad por QEMSCAN (Figura 4). La toma de estas pequeñas muestras de los fragmentos permitió su conservación, ya que son únicos, facilitando un análisis futuro mediante otros métodos (Figura 3).

La petrografía cerámica mediante la observación de láminas delgadas en microscopio de luz polarizada permite establecer características mineralógicas, texturales e inferir implicancias tecnológicas. Desde el punto de vista arqueológico, permite diagnosticar las diversas elecciones de los alfareros del pasado.

Por su parte, la técnica QEMSCAN (SEM-EDS) de análisis mineralógico automatizado, ofrece datos cuantitativos mediante la determinación de la composición química de los diferentes minerales que constituyen la pasta. En este caso, el segmento de cerámica es montado en una briqueta de resina epóxica y leído a través del escaneado, dando como resultado mapas mineralógicos totales o específicos, tablas porcentuales y de porosidad, entre otros. Además, el fragmento queda preservado en la briqueta y se puede usar para el estudio por otras técnicas analíticas (Figuras 3 y 4) (Riera Soto, 2019).

La técnica QEMSCAN es un sistema automatizado que permite realizar análisis químicos y mapas minerales de alta resolución y funciona gracias a un SEM (Scanning Electron Microscope) y cuatro espectrómetros de rayos X (EDS: energydispersive $X$-ray spectrometers). $\mathrm{Al}$ incidir el haz de electrones del SEM sobre la muestra se generan backscattered electrons (BSE) que son medidos para localizar las partículas individuales dentro de la muestra. Posteriormente, se realiza un barrido sobre la superficie en una grilla de espaciamiento definida por el usuario, con una resolución comúnmente entre $0.2 \mu \mathrm{m}$ y $25 \mu \mathrm{m}$. El haz de electrones genera la emisión de rayos X producto de la liberación de alta energía emitida por los electrones dentro del 
elemento, que ocupan los espacios dejados por los electrones de niveles energéticos más bajos y que son movidos de su posición. Los espectros de rayos $\mathrm{X}$ obtenidos son comparados con una base de datos y de esta forma se identifican todas las fases minerales presentes en la muestra en cada espacio de la grilla (Contreras Torres, 2015)

Los análisis mediante esta técnica se realizaron en la Unidad de Equipamiento Científico MAINI-UCN, Universidad Católica del Norte (Chile) a través de un convenio con el Proyecto ArqueoLab-UBA. La especialista Camila Riera Soto, asesora y colaboradora del proyecto, es quien llevó adelante su aplicación. Más allá de la evaluación del potencial de la técnica, que es por demás satisfactoria, cabe destacar que para su aplicación se cuenta con una base de datos con patrones mineralógicos automatizados de cerámicas procedentes del ámbito circumpuneño de la región II de Chile, haciendo posible comparar la tecnología cerámica entre regiones y conocer datos sobre la posible procedencia de los materiales cerámicos (Acevedo et al., 2019; Riera Soto, 2019; Riera Soto et al., 2018).

Discusión y síntesis de los resultados preliminares de petrografía cerámica y QEMSCAN

Los resultados obtenidos indican que las 4 muestras analizadas presentan similitudes mineralógicas entre algunas de ellas y diferencias a nivel intra-conjunto. Las muestras 2, 3 y 4 presentan altas concentraciones de muscovita en la matriz $(<30 \%)$, a diferencia de la muestra 1 que presenta una matriz rica en arcillas y cuarzo.

En el caso de las inclusiones, existen diferencias entre la muestra 1-2 y la 3-4, ya que las primeras presentan cuarzos bien seleccionados y líticos, además de concentraciones de arcillas y óxidos de Fe-Ti para la muestra 1 y biotitas para la 2 y en cambio las dos últimas ( 3 y 4) presentan principalmente cuarzos mal seleccionados y carbonatos, además de finos feldespatos (Figura 4).

En cuanto a las materias primas, las muestras 2, 3 y 4 presentan una matriz análoga, rica en muscovita, probablemente de origen metamórfico. En cambio, la muestra 1 presenta una pasta texturalmente diferente, lo que deja interpretar que la fuente de aprovisionamiento está ubicada en un ambiente geológico distinto a las tres primeras (Figura 4). La muestra 1 se discrimina de los otros fragmentos por rasgos petrográficos y tecnológicos y podría estar relacionada con la cerámica proveniente del sector del Alto Loa, posiblemente asociada al tipo Los Morros A (Sinclaire, 2004). La muestra 2 presenta características petrográficas foráneas a la quebrada, pudiendo ser su origen el sur boliviano (Acevedo, 2014), mientras que las muestras $3 \mathrm{y}$ 4 son petrográficamente homólogas y difieren en los rasgos tecnológicos, también tratándose de un posible origen foráneo a la quebrada, posiblemente a la región del Alto Loa.

En relación a la circulación de estos materiales, las muestras son petrográficamente disímiles a las cerámicas halladas en sitios cercanos a San Pedro de Atacama y Tarapacá en el norte de Chile (Riera Soto, 2019), siendo regiones también vinculadas al intercambio con la región circumpuneña. Por lo tanto, se debe

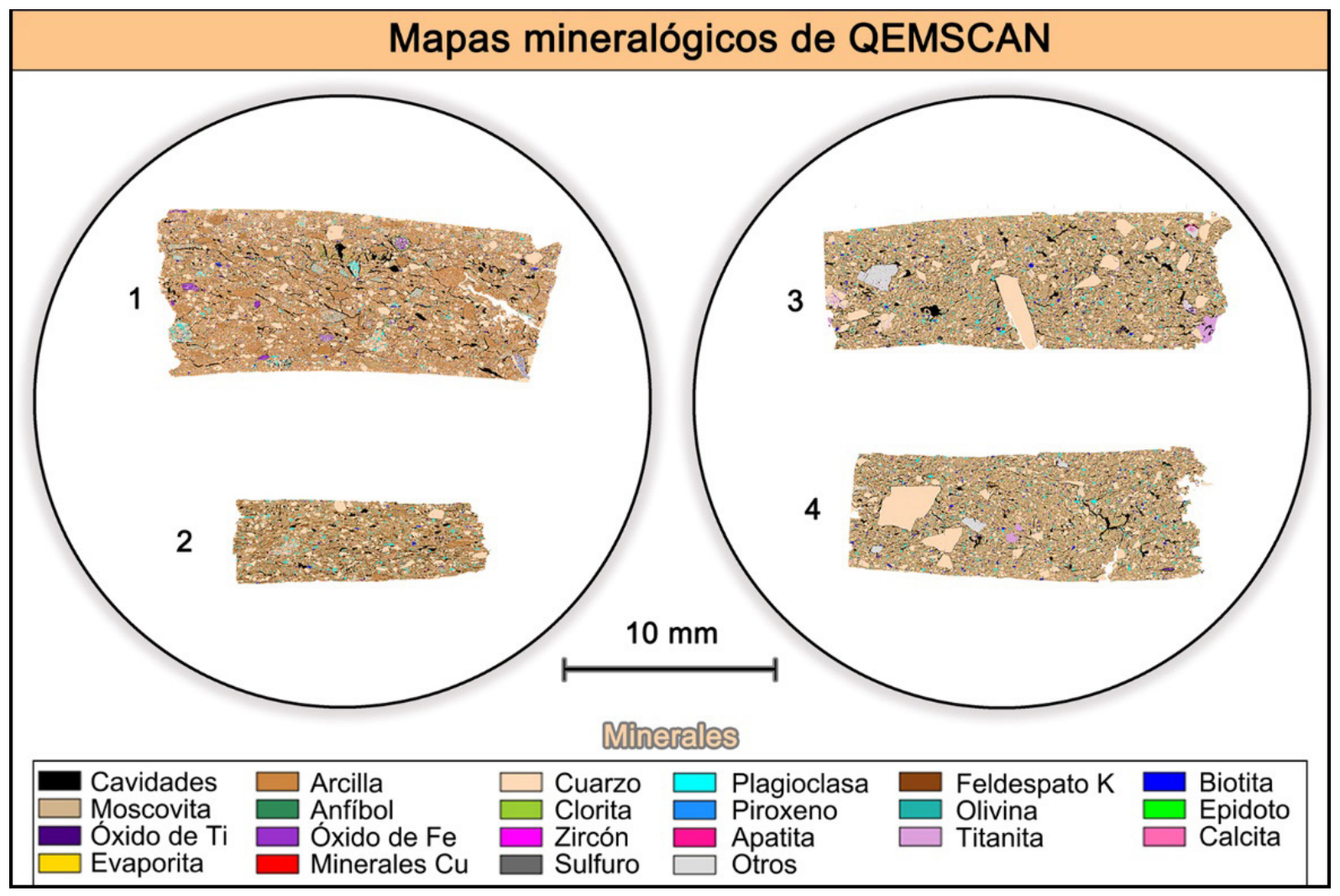

Figura 4. Mapas mineralógicos de los cuatro fragmentos del caso 1 obtenidos mediante la técnica QEMSCAN. 
seguir profundizando en los resultados sobre estos materiales, que guardan alguna posible relación con cerámicas de los sitios del Alto Loa, sur del Salar de Atacama y/o sur de Bolivia. Sin embargo, los resultados avalan la hipótesis sobre un origen alóctono a la región de la Quebrada de Humahuaca, confirmando las interacciones sociales que establecieron los grupos aldeanos del período a través de la circulación de objetos.

Asimismo, cuando la muestra original fue ampliada mediante el análisis petrográfico en combinación con el uso de la técnica QEMSCAN, fue posible comparar la tecnología cerámica entre regiones y conocer datos sobre la posible procedencia del puco (Acevedo, 2015, 2018; Riera Soto et al., 2018). Es importante destacar, que al sumar muestras de diferentes regiones se van agregando patrones mineralógicos a la base de datos QEMSCAN, lo que permite ampliar la información para comparar y caracterizar distintas muestras.

En esta etapa de investigación, los estudios estuvieron focalizados en la caracterización y procedencia de los materiales del contexto de la estructura $\mathrm{F}$ y en la evaluación de esta nueva técnica poco aplicada hasta ahora en la arqueología. Sin embargo, debido a su potencia y a la profundización en las características tecnológicas a partir de los estudios petrografía cerámica por microscopio de luz polarizada, se dará continuidad a los análisis para ampliar la información sobre la circulación de objetos y materiales cerámicos del NOA y el norte de Chile.

\section{Síntesis de resultados del caso 1}

La información proveniente de múltiples líneas de evidencia permitió recolectar datos concernientes a las prácticas rituales como también a aspectos económicos y sociales. En efecto, el análisis tecnológico del puco permitió determinar que su pasta difiere de las producidas en la Quebrada de Humahuaca, asemejándose a los materiales cerámicos conocidos como Los Morros variante A de la zona del río Loa, en el norte de Chile (Acevedo, 2011, 2014). Este dato, junto con la presencia del caracol terrestre de la vertiente oriental, resulta indicativo de la existencia de lazos de interacción o intercambio con grupos que habitaban otras regiones, aunque aún es desconocido de qué modo.

Asimismo, el contexto hallado aporta información indirecta sobre las prácticas económicas de estos grupos, indicando posiblemente una mayor relevancia de las prácticas productivas. Por un lado, el análisis de isótopos estables en los restos humanos permitió inferir una dieta principalmente de proteínas y grasas animales, complementada con el consumo de plantas de tipo $\mathrm{C}_{3}$, como quinoa, tubérculos y calabaza (Olivera \& Yacobaccio, 1999). Por otro lado, la presencia de morteros, artefactos generalmente empleados en el procesamiento de alimentos vegetales, podría estar reflejando una importancia creciente de la agricultura (Hernández Llosas, 1998), aunque presentan rasgos de uso para el procesamiento de mezclas pigmentarias (Acevedo, 2010).

Los estudios precedentes fueron complementados con información arqueológica y antropológica, que remite a un conjunto de prácticas que son relevantes para vincular con las particularidades del contexto, tales como tradiciones rituales, tecnologías de producción cerámica y modalidades de circulación de personas o grupos, entre las principales. Los resultados en conjunto permitieron plantear un origen del contexto asociado al tránsito desde las zonas altas hacia las zonas orientales o yungas, pasando por quebradas altas y en donde se visualizan elementos no locales a la Quebrada de Humahuaca.

Si bien, en la década de los 90 , el contexto de la estructura F fue interpretado como una estructura funeraria (Hernández Llosas, 1998), en la actualidad, se plantea que los indicadores mencionados en el desarrollo de este texto, nos conducirían a reflexionar sobre un comportamiento ritual asociado a una posible estructura ceremonial (Acevedo, 2014; Leoni y Hernández Llosas, 2015). Ya que, además, no se han registrado otras evidencias de ocupación del alero contemporáneas con este contexto (Hernández Llosas, 1998, 2000).

En síntesis, el contexto de hallazgo de la estructura $\mathrm{F}$ es considerado, en la actualidad, como un conjunto de materiales que fueron reunidos para formar parte de una ofrenda como producto de algún ritual propiciatorio, con un repertorio de formas y tamaños característico de dichos contextos (Acevedo, 2011, 2014; Palma, 1998). A su vez, estarían representando algunas de las prácticas sociales que reflejan la fluidez cultural entre poblaciones de diferentes lugares dentro del área circumpuneña (Acevedo, 2011, 2014).

\section{Caso 2: diseños, pigmentos y fronteras de interacción}

Para el segundo caso de estudio se analizaron materiales cerámicos polícromos arqueológicos denominados "vírgulas o comas", que tienen una amplia pero desigual distribución espacial y que constituyen hallazgos en cantidades limitadas en sitios arqueológicos de la Puna norte y central y la Quebrada de Humahuaca, ambas regiones pertenecientes a la provincia de Jujuy (Argentina) (Figura 1 y 5) (Acevedo, 2011; Nielsen, 1997; Zaburlín, 2012).

Las vasijas de estas características son halladas en sitios arqueológicos de las regiones mencionadas desde el Período de Desarrollos Regionales (900-1430 d.C.), transitando el momento de dominio incaico (1.430-1.536 d.C.) y hasta momentos postcontacto con el español (Acevedo, 2011; Nielsen, 1997; Cremonte, 2006; Zaburlín, 2012), lo cual nos conduce a reflexionar sobre el movimiento de individuos, materiales y piezas cerámicas entre fronteras, con un posible e importante uso y consumo ritual y/o ceremonial (Acevedo, 2011).

En la región de la Puna, la cerámica polícroma presenta mayor variabilidad en sus diseños, formas y tamaños, mientras que en la región de la Quebrada de Humahuaca aparece en piezas pequeñas y acompaña al estilo quebradeño negro sobre rojo (Figura 5) (Acevedo, 2011; Nielsen, 1997; Zaburlín, 2012). Algunos investigadores caracterizan a este tipo como una variedad de la cerámica denominada negro sobre rojo, característico de la Quebrada de Humahuaca. Sin embargo, también es considerado un grupo en sí mismo, en el que algunos de sus diseños más singulares disminuyen su frecuencia hacia finales del Período de Desarrollos Regionales (Deambrosis \& de Lorenzi, 1975; Nielsen, 1997, 2001). El diseño de "vírgulas o comas" aparece también asociado al llamado "lunares blancos" (Acevedo, 2011; Deambrosis \& de Lorenzi, 1975; Nielsen, 1997; Zaburlín 2012). Los investigadores que han estudiado estos materiales los han mencionado bajo diversos nombres locales de sitios de la Quebrada de Humahuaca como, por ejemplo, Alfarcito Polícromo, Isla Polícromo, Peña Colorada Tricolor, entre otros, así como con nombres locales de la Puna como Casabindo tricolor, Queta Polícromo o directamente Puna tricolor, utilizando los clásicos ordenamientos tipológicos de principios 


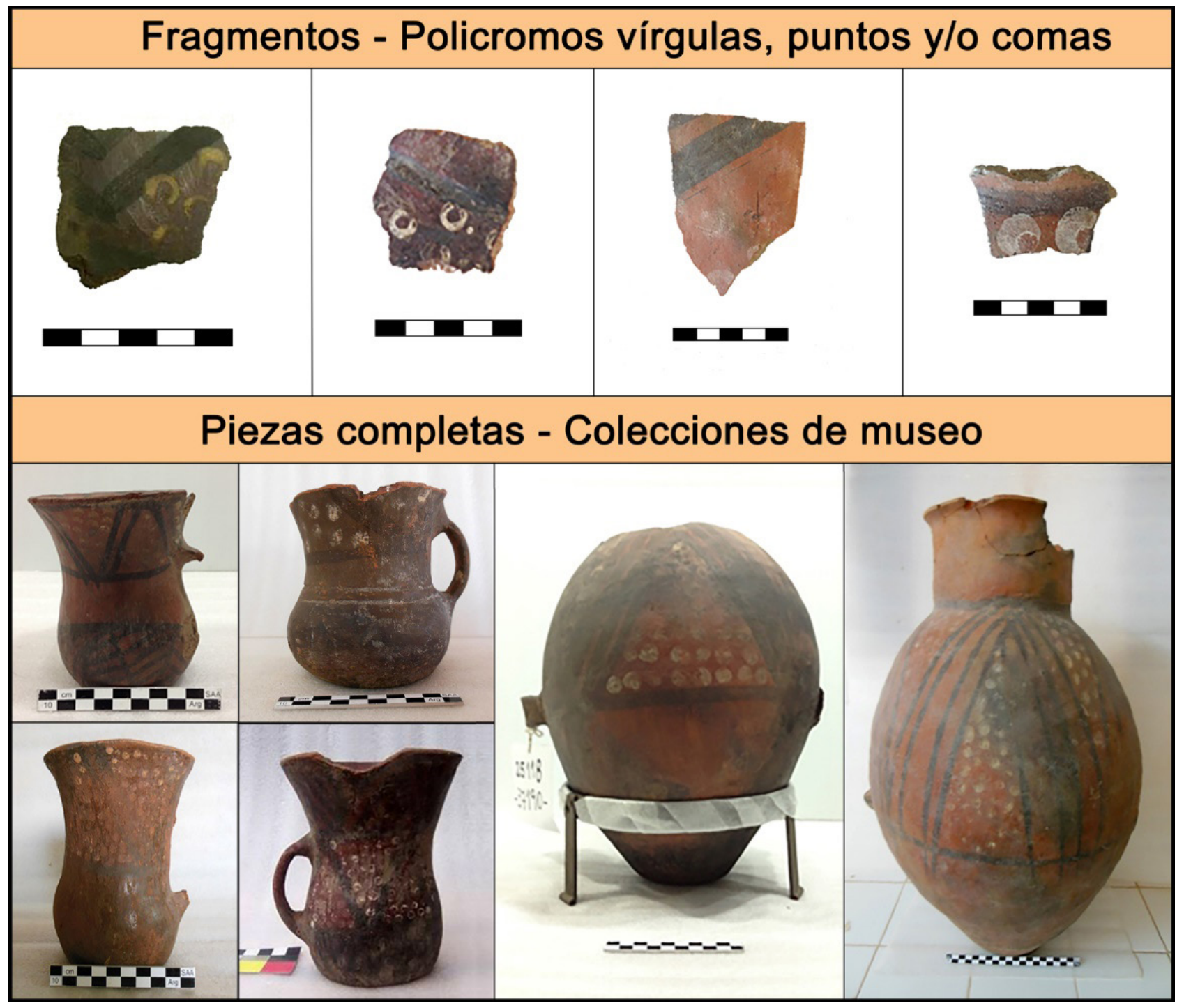

Figura 5. Fragmentos y vasijas del estilo "vírgulas, comas y/o lunares blancos".

Tiestos y piezas de la Quebrada de Humahuaca (izquierda) y fragmentos y vasijas de la Puna norte y central (derecha).

del siglo XX (Cremonte, 1985; Rivolta, 1997; López, 2004; Zaburlín, 2012; entre otros). Estas piezas compartirían, además del diseño, la particularidad de poseer inclusiones no plásticas de color blanco en la composición de sus pastas (Acevedo, 2011). Dichas pastas son parte constitutiva de diferentes tipos de vasijas y estilos que son hallados en diversos sitios arqueológicos de la región circumpuneña, aunque algunas de ellas se las adjudica a la tecnología cerámica Yavi-Chicha (Ávila, 2005; Cremonte, 2006).

Esta amplia variabilidad y distribución plantea interrogantes sobre la comprensión de las prácticas sociales responsables de la manufactura de estas vasijas y sus implicancias en los procesos de interacción regional.

Hace unos años se realizaron diversos estudios arqueométricos a una muestra acotada de fragmentos de este estilo cerámico de diferentes sitios de la Puna jujeña y la Quebrada de Humahuaca mediante espectroscopía Raman, DRX y SEM-EDS (Acevedo, 2011; Marte et al., 2012; Freire et al., 2015). Las técnicas analíticas usadas en ese momento resultaron innovadoras por ser no destructivas, permitiendo estudiar la muestra sin generar pérdidas o daños en los fragmentos originales. Como resultado, se observó una amplia variabilidad tecnológica en mezclas pigmentarias dentro del conjunto denominado "vírgulas o comas", a la vez que se evaluó el nivel de resolución de dichas técnicas, aunque quedaron algunos interrogantes por responder (Acevedo, 2011, 2018; Marte et al., 2012; Freire et al., 2015)

Asumiendo que, hasta el momento, la aparición de este estilo en sitios arqueológicos es restringida y limitada, se decidió ampliar la muestra con conjuntos de piezas enteras de este estilo que pertenecen a colecciones de diferentes museos. En este sentido, se generaron estrictos protocolos de actuación que permitieron abordar este tipo de material para continuar con los estudios sin afectar las piezas cerámicas completas de colección (Acevedo, 2013; Acevedo y Herrera, 2016).

En esta sección se retoman y re-testean algunos resultados 
obtenidos a partir de los estudios realizados a los fragmentos cerámicos de excavación, de la primera etapa, que se amplían integrando los datos resultantes de las muestras extraídas de las colecciones de piezas completas alojadas en museos. Asimismo, se mencionan los desafíos metodológicos sobre la toma de muestras y la utilización de nuevas tecnologías para la caracterización de materiales, como microestratrigrafías de pigmentos, Raman IFT-IR, microscopio UV-IR, entre otras. Los resultados de los análisis sobre la caracterización de diseños y pastas de este tipo de piezas permitieron obtener información para acercarnos a reconocer las dinámicas fronterizas dadas en el pasado entre poblaciones de la región del ámbito de la Quebrada de Humahuaca y sus áreas adyacentes (Acevedo, 2015).

Afortunadamente, los estudios en pigmentos sobre cerámicas arqueológicas han avanzado en las últimas décadas desde la incorporación de diversos métodos para su análisis, provenientes de las ciencias físico-químicas en combinación con otras líneas de evidencia como, por ejemplo, la etnografía o la experimentación (Acevedo, 2018).

Es así que, los diseños y colores plasmados sobre las superficies de vasijas cerámicas arqueológicas que indican un comportamiento tecnológico organizado para tal efecto y las recetas sobre los procesos utilizados por los alfareros del pasado, son comprendidas por especialistas que se valen de diferentes técnicas arqueométricas en combinación con diversas líneas de evidencia.

Materiales y métodos de estudio del caso 2
Materiales cerámicos de colección de museos

El estudio de piezas completas de colección que se encuentran alojadas en museos es de sumo interés para la contextualización del registro arqueológico de excavación. Sin embargo, la recuperación de datos a través de técnicas arqueométricas resulta compleja, ya que son pocas las posibilidades de trasladar los objetos para estudiarlos en laboratorios especializados.

Las piezas estudiadas en la investigación que se encuentra en curso provienen de diversos museos, del Museo Arqueológico y Antropológico Dr. Eduardo Casanova de Tilcara (FFyL, UBA), el Museo Arqueológico Municipal de Humahuaca, el Museo Etnográfico Juan B. Ambrosetti (FFyL, UBA) y el Museo de La Plata (Facultad de Ciencias Naturales y Museo, UNLP).

Debido a la cantidad de material en estudio, al desarrollo de la temática y a la extensión de este trabajo, presentaremos una selección de datos y resultados provenientes del análisis de diseños y del estudio de las inclusiones en resina de pigmentos o mezclas pigmentarias para microestratigrafías pertenecientes al conjunto de muestras del Museo Arqueológico y Antropológico Dr. Eduardo Casanova, dado por estudios sobre veinte micromuestras, que corresponden a los sitios arqueológicos de Campo Morado, Quebrada de la Cueva y Pueblo Viejo de Humahuaca (Quebrada de Humahuaca) y Doncellas, Santa Catalina y Casabindo (Puna jujeña).

En el estudio de las piezas y los fragmentos de cerámica

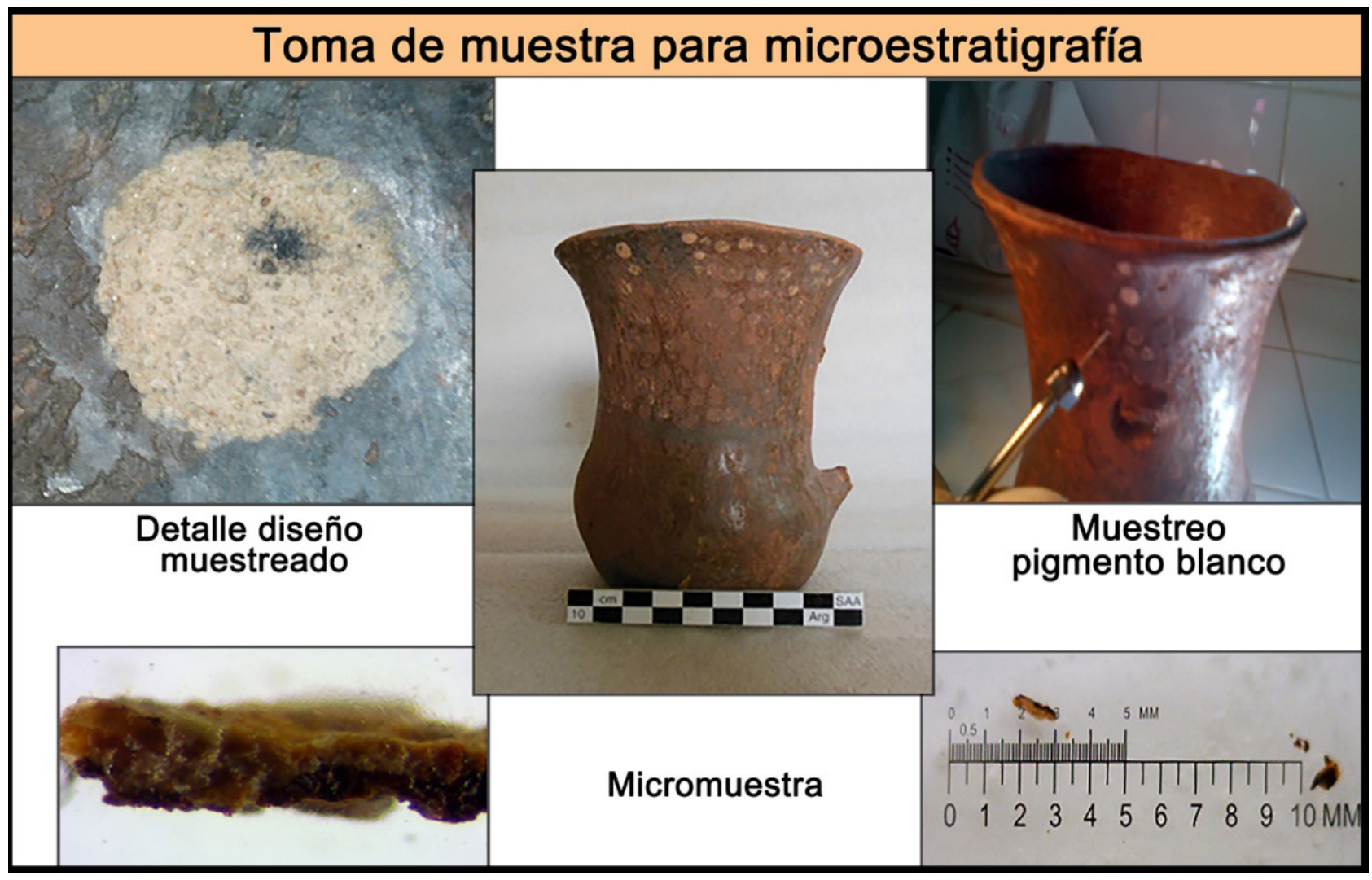

Figura 6. Toma de muestras para microestratigrafías: detalle del pigmento blanco donde se observa la matriz sobre una pieza de la Quebrada de Humahuaca. 
de este estilo es característico observar al menos tres tipos diferentes de estratos en su superficie, que forman sus diseños y que dan como resultado el efecto polícromo, en el cual se destaca visualmente los diseños en círculo, medio círculo o círculo completo de color blanco (Figuras 5, 6 y 7) (Acevedo, 2011).

En relación con el estudio de diseños y mezclas pigmentarias de piezas enteras de colección alojadas en depósitos de museos, se plantearon tres tipos de estrategias de trabajo in situ, dependiendo de las formalidades de cada museo. La primera estrategia estuvo vinculada a la toma de muestras sobre la superficie de piezas cerámicas para la generación de microestratigrafías y la segunda, fue la posibilidad de utilizar FRX portátil para el diagnóstico. La tercera estuvo vinculada al registro fotográfico óptico multiespectral, usando filtros en blanco y negro y color mediante App Store del Software PhotoBooth de Apple con utilización de cámara Sight, accesorio de microscopía y documentación microfotográfica por medio de microscópico Dino-Lite 4125 (USB). Para ello, se crearon protocolos de actuación según el caso de estudio y los requerimientos específicos de cada institución. En algunos casos, se pudo aplicar las tres estrategias metodológicas, mientras que en otros no fue posible, sin embargo, en todos los casos se registraron datos para análisis en laboratorio.

La aplicación de la técnica microestratigráfica es utilizada como una herramienta de recolección de información para el desarrollo de trabajos de investigación, conservación y gestión de pigmentos arqueológicos, históricos o artísticos. Esta técnica previene riesgos de impacto, deterioro y pérdida de datos que se puedan generar sobre el material durante la toma de la muestra y en el posterior almacenamiento. En este caso, se emplearon protocolos de muestreo y de conservación para el uso de perspectivas analíticas y el trabajo interdisciplinario, contemplando las normativas aplicadas en la conservación de bienes culturales a nivel internacional (Acevedo \& Herrera, 2016, Herrera \& Acevedo, 2019).

La técnica de microestratigrafía de pigmentos cerámicos por inclusión consiste en la extracción de una micromuestra de una o varias capas de pigmento, mezclas pigmentarias o matriz resultante del muestreo de zonas representativas de diseños que están sobre la superficie de las vasijas. Posteriormente y en laboratorio, se realiza la inclusión en resina acrílica, en la cual queda contenido el pigmento en forma de estratigrafía, junto con la matriz y la superposición del o los diseños. De esta manera, la muestra del material queda contenida en un soporte seguro, que facilita su manipulación mecánica para su estudio con microscopio o con diferentes instrumentos analíticos. Este procedimiento permite la resolución de problemáticas de muestreo, conservación, almacenamiento y gestión, ya que no compromete al objeto en estudio (Figura 6). Una de las ventajas de este procedimiento, es que proporciona un soporte para el material pigmentario compatible con el instrumento analítico, permite analizar la muestra microestructuralmente y observar la superposición en los diseños, su estructura y así poder reconocer patrones tecnológicos de los alfareros prehispánicos.

El tamaño de las micromuestras suele variar en relación con el acceso y estado de conservación del objeto/material, así como los estudios que se plantean realizar (Acevedo \& Herrera 2016; Herrera \& Acevedo, 2019). Generalmente, se considera que el tamaño de las muestras de pigmentos debe tener entre 0.5 y 2 $\mathrm{mm}$ de espesor máximo, sin superar los $2 \mathrm{~mm}^{2}$. En la práctica, se ha observado que puede variar entre 0.5 a $1 \mathrm{~mm}$ en muestras de una sola capa de pigmento, de 1.5 a $2 \mathrm{~mm}$ en muestras de dos a tres capas y entre 2.5 a $3 \mathrm{~mm}$ en muestras completas con matriz.

Microespectroscopía Raman IFT-IR para el análisis de composiciones pigmentarias

La espectroscopía Raman se basa en los fenómenos de dispersión inelástica de la luz monocromática que a través de un láser interactúa con el sistema vibracional, produciendo la excitación de los fotones entre el rango de luz visible, ultravioleta o el infrarrojo cercano. Existen en el mercado varios aparatos analíticos de este tipo, algunos adosan sólo la sonda para análisis Raman, otros un microscopio de altos aumentos (microespectroscopía Raman) y los más avanzados tienen incorporado un microscopio confocal que se completa con un equipo accesorio infrarrojo. Aunque, la espectroscopía infrarroja proporciona una información similar, ambas son complementarias.

Si bien, esta técnica en arqueología tiene muchas aplicaciones, una de las más usadas es para la caracterización composicional de pigmentos y mezclas pigmentarias de diseños de cerámicas arqueológicas, ya que se puede realizar sobre la superficie de los fragmentos sin dañarlos.

Se analizaron superficies de fragmentos y microestratigrafías provenientes de las muestras de colección de museos, para este caso un total de diez muestras, que provienen de los sitios arqueológicos Pintoscayoc 1 y Gasoducto, localizados en la Quebrada de Humahuaca, Abralaite y Doncellas de la Puna norte y central de Jujuy, algunos de los fragmentos fueron estudiados, hace ya unos años y en una primera etapa, como se mencionó más arriba, con un equipo Lab-Ram HR (Horiba Jobin Youn, Láser de 514,5 de baja potencia 0,2 ) para no degradar la muestra. Sin embargo, con esta potencia y este equipo, no se pudo discriminar algunos de los componentes que se pretendían estudiar, particularmente los orgánicos, ya que el láser indicaba una alta fluorescencia.

A partir de dar cuenta de las problemáticas derivadas de los estudios previos, relacionadas con la caracterización específica de los pigmentos blancos, la superposición de diseños negros de distinta composición pigmentaria y del no diagnóstico composicional de una capa transparente, que aparecía en varios fragmentos por encima de las vírgulas a modo de recubrimiento en sitios de la Quebrada de Humahuaca, se decidió aplicar una nueva tecnología sobre las muestras preparadas en diversos soportes. Es por ello que, para el avance en la caracterización de pigmentos y mezclas pigmentarias de las cerámicas estudiadas, se implementó el uso de Raman con los equipos DXR2 y DXR2i de la marca Thermo Scientific, los cuales permiten complementar el estudio con microscopio confocal y equipo accesorio FT-IR Nicolet i55. Este último, es utilizado frecuentemente para obtener mejores resultados en muestras orgánicas. Dicha tecnología, cuya versatilidad y tamaño del equipo facilita la tarea de análisis químico, requiere de la capacitación de un experto o arqueólogo especializado (Figura 7).

En el caso de los pigmentos blancos, se nos presentó una reflexión sobre el uso de ciertas técnicas y la necesidad de combinar diversas metodologías para la caracterización de las mezclas pigmentarias de este tipo, ya que no se habían obtenido resultados claros en algunos compuestos en una primera etapa con el equipo Lab-Ram HR. Es así como, se re-testearon muestras de fragmentos de la Quebrada de Humahuaca y de la Puna y las 


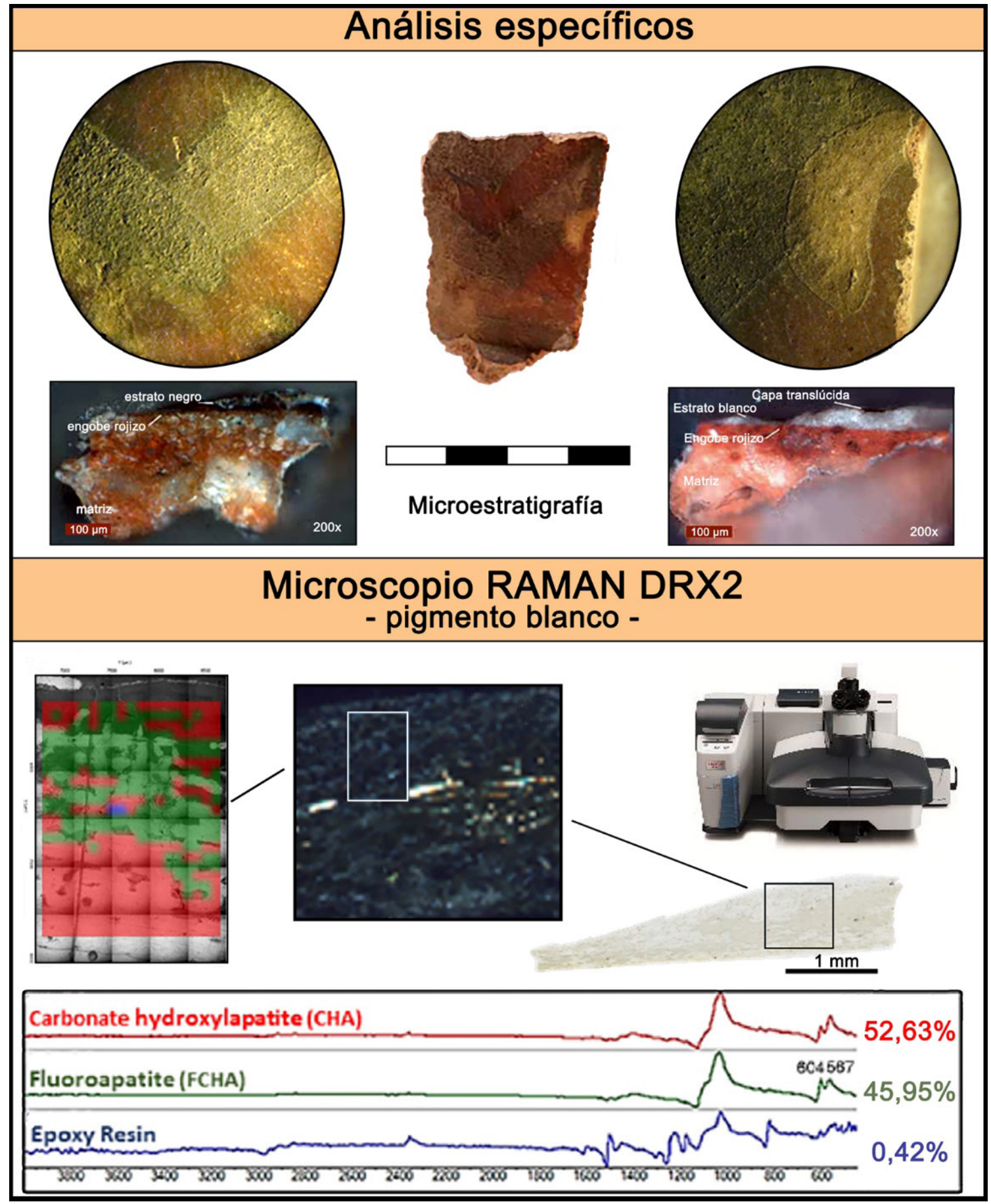

Figura 7. Microscopía óptica sobre fragmento del estilo "vírgulas o comas" y sobre microestratigráficas: se observan los estratos que forman el diseño polícromo y la capa transparente sobre diseño blanco (arriba). Microscopio Raman DRX2 de mesada: espectros de compuestos hallados en pigmento blanco, mapeo e imagen de microscopio confocal de segmento de hueso dentro de la mezcla pigmentaria blanca (abajo).

muestras provenientes de las colecciones de museos con el fin de obtener un diagnóstico más preciso, siendo que su velocidad de muestreo y resolución permitió resolver la caracterización de pigmentos blancos y, en algunos casos, la pátina transparente que cubre parte de esos diseños (Figura 7). 
Microscopio UV-IR para determinar patrones ópticos de pigmentos

El microscopio UV-IR de conexión USB es una de las técnicas analíticas recientes de fácil acceso para los investigadores. La técnica permite obtener un espectro visible mediante la emisión de frecuencias diferenciales en la escala de longitud de onda de luz ultravioleta y/o de luz infrarroja (Figura 8). Al utilizarlo sobre la superficie de los materiales, se puede observar la estructura y microestructura a diferentes aumentos y utilizar un software que permite superponer y organizar imágenes y datos multimodales.

El objetivo de su utilización sobre diez muestras de fragmentos cerámicos con diseño y de microestratigrafías, fue observar la estructura de los pigmentos que ya había sido diagnosticada por los nuevos equipos de microespectroscopía Raman y experimentar e indagar el tipo de emisiones en el espectro visible para la conformación de patrones pigmentarios. A partir de ello, se obtuvieron diferentes resultados sobre las diversas muestras.

En el análisis se destacaron detalles de la morfología de los diseños en superficie como marcas de la técnica de alisado, marcas de instrumentos empleados para realizar los elementos figurativos, deterioros en las representaciones, relieves y bajorrelieves del acabado de superficie, posibles "repintes", la textura de ciertos elementos figurativos y la superposición de varios estratos, entre ellos el elemento de las vírgulas. Además, en algunos de los pigmentos blancos se identificaron micro fragmentos de hueso correspondientes al compuesto de hidroxiapatita según la señal obtenida por la técnica Raman (Figura 7).

En referencia al potencial de este microscopio y en relación con el diagnóstico sobre patrones pigmentarios, se ha observado que esta técnica permite la visualización de las texturas y estructuras de los pigmentos, así como permite diferenciar la reacción en el visible de los diversos compuestos de las mezclas pigmentarias.

\section{Síntesis de resultados del caso 2}

Las piezas completas de colección del Museo Arqueológico y Antropológico Dr. Eduardo Casanova de Tilcara (FFyL, UBA), de la Puna y la Quebrada de Humahuaca presentan variabilidad en las técnicas primarias de construcción de las vasijas y en los tratamientos de superficie. Las mismas muestran un patrón recurrente en las técnicas de construcción de las vasijas de la Quebrada de Humahuaca. Sin embargo, la distribución de los diseños y de los campos de decoración es equiparable en todas las cerámicas enteras y en los fragmentos de excavación de ambas regiones, así como el efecto visual dado por las representaciones de "vírgulas o comas" (Figuras 5 y 6).

En los tratamientos de superficie se detectó la presencia de hidroxiapatita $\left(\mathrm{Ca}_{5}(\mathrm{PO} 4)_{3}(\mathrm{OH})\right)$, como responsable del color blanco en el grupo de muestras de la Puna norte (Doncellas, Santa Catalina y Casabindo) mientras en el grupo de la Puna central (Abralaite) y la Quebrada de Humahuaca (Gasoducto) los blancos se indicarían la presencia de carbonatos de calcio $\left(\mathrm{CaCO}_{3}, \mathrm{TiO}_{2}\right)$. Sin embargo, no se ha podido distinguir el responsable del color blanco en las muestras del sitio Pintoscayoc 1, aunque en muestras de estilo tricolor del conjunto del sitio se detectó hidroxiapatita y se observó pequeños fragmentos de hueso por microscopio UV-IR (Figura 8). En los colores rojizos de los engobes de todas las muestras, tanto de la Puna como de la Quebrada de Humahuaca, se detectaron compuestos relacionados con óxidos de hierro.

La aplicación combinada de técnicas arqueométricas ha permitido identificar el uso de diferentes compuestos para la preparación de pigmento blanco, uno a base de fosfatos (Figura 7), y otro a base de compuestos de calcio y titanio. El primero ha sido observado en fragmentos de la Puna norte, otros han sido detectados en fragmentos de las regiones de la Puna central y la Quebrada de Humahuaca. Esto indica que el uso de un compuesto dado no necesariamente corresponde a una región arqueológica y geográfica en particular.

Por otra parte, se realizaron análisis sobre sedimentos de color blanco provenientes de la región norte de la Quebrada de Humahuaca, específicamente del sector Peñas Blancas localizado dentro del perímetro del pueblo de Humahuaca. Dichos análisis detectaron carbonatos de calcio $\left(\mathrm{CaCO}_{3}\right)$, lo que indica que los recursos para obtener el color blanco estaban disponibles dentro del área de la Quebrada de Humahuaca, aunque aún falta determinar si fueron seleccionados especialmente para ese uso.

En los diseños negros se observó que las muestras de la Puna fueron decoradas con mezclas de compuestos de manganeso $(\mathrm{Mn})$, en algunos casos jacobsita $\left(\mathrm{MnFe}_{2} \mathrm{O}_{4}\right)$. En cambio, en las halladas en la quebrada se detectó en algunas de ellas carbón (C) + hematita $\left(\mathrm{Fe}_{2} \mathrm{O}_{3}\right)$ y magnetita $\left(\mathrm{Fe}_{3} \mathrm{O}_{4}\right)$. Esto es coincidente con la tradición tecnológica descrita para la Quebrada de Humahuaca (Botto et al., 1998; Acevedo, 2011, 2014; Acevedo et al., 2012), aunque en la del sitio Gasoducto se detectó jacobsita, al igual que en muestras de la Puna.

Los compuestos de manganeso que permiten obtener el color negro de los diseños son detectados en la región de la Quebrada de Humahuaca luego de la entrada incaica (López, 2004). Lamentablemente, no existen otros estudios analíticos comparativos realizados con técnicas arqueométricas sobre superficies cerámicas en la región de la Puna y, por lo tanto, no se puede saber cuáles serían las recetas pigmentarias propias de esa región. Por su parte, en la Quebrada de Humahuaca existen varios trabajos relacionados con la tecnología del color (Acevedo, 2011; Acevedo et al., 2012; Acevedo, 2014; Botto, Barone, Cremonte \& Sánchez; Cremonte, 1991; Cremonte et al., 1997; López, 2004; entre otros).

En las muestras estudiadas se observaron diferentes tipos de acabados de superficie y diversas texturas, que sugieren el uso de hueso molido (hidroxiapatita) para el color blanco de algunos de los diseños de las muestras analizadas y caracterizadas por las técnicas descritas, siendo la hidroxiapatita un componente que se ha encontrado en otros ejemplos del NOA (De la Fuente, Kristcautzky \& Toselli, 2007; De la Fuente \& Martínez, 2008; Palamarczuk, 2007). La relación de este componente mineralógico con un comportamiento ritual por parte de los alfareros no ha sido estudiada en profundidad, pero deja abiertas líneas de investigación sobre la significación de su presencia en la decoración de las vasijas.

Es sugerente que en muchos de los diseños blancos de piezas de la Quebrada de Humahuaca se observe una capa transparente recubriendo el diseño y que, al analizarla por Raman IFT-IR, se encuentren señales compatibles con grupos de amida, lo que indica la presencia de proteína (Figura 7), dato importante que merece continuar explorando.

La relación temperaturas de cocción y pigmentos sugiere que las muestras de la Puna, pudieron ser cocidas a temperaturas mayores a las utilizadas por los alfareros del pasado en la Quebrada de Humahuaca, ya que la detección de jacobsita 


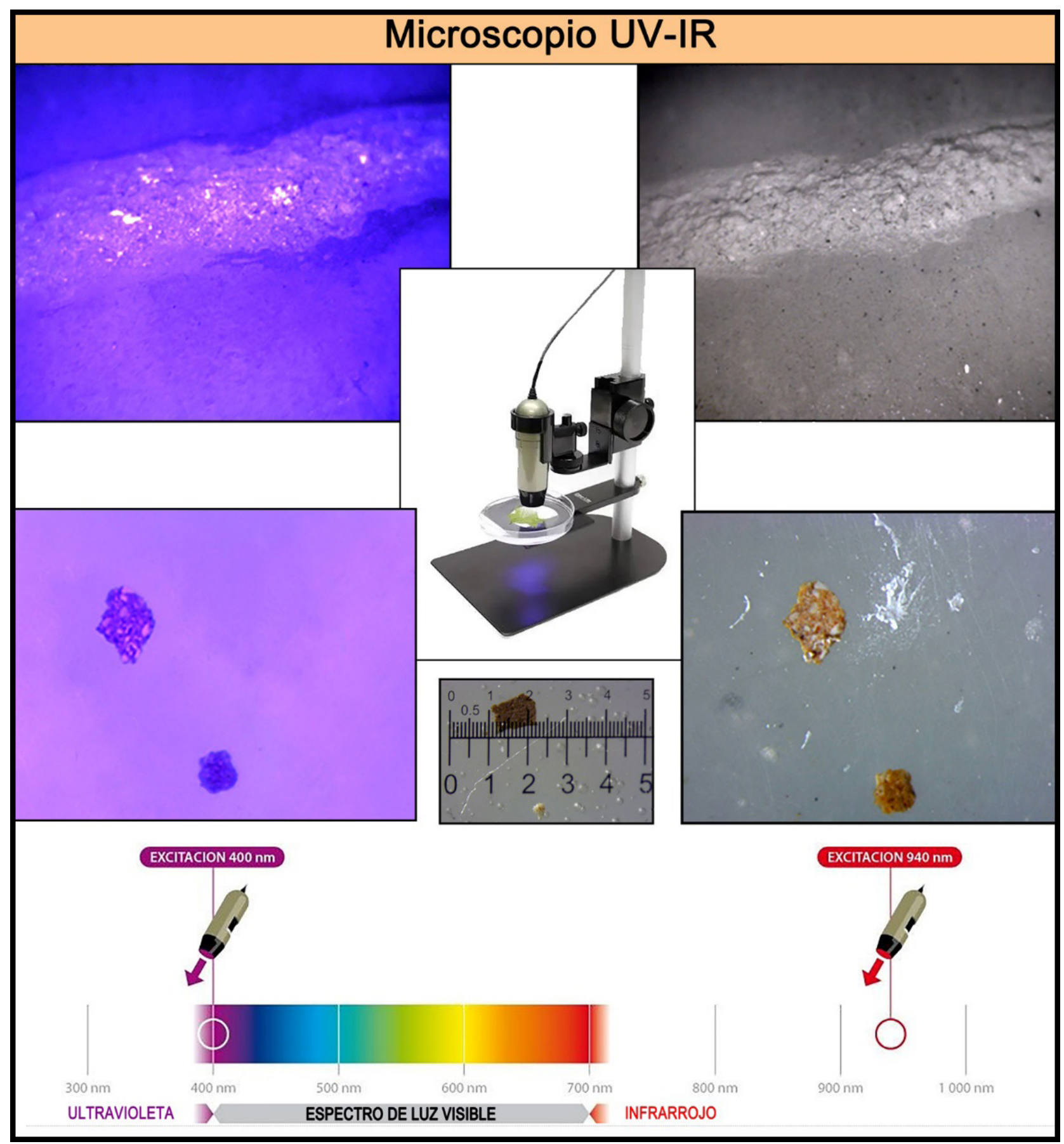

Figura 8. Microscopio UV-IR: textura de pigmento blanco sobre la superficie del fragmento (arriba derecha), imagen en UV (arriba izquierda), ambas muestras en 200x. Muestra de pigmento blanco en inclusión de resina en la cual se distinguen microfragmentos de hueso (abajo izquierda) y misma imagen en IR (abajo derecha).

$\left(\mathrm{MnFe}_{2} \mathrm{O}_{4}\right)$ nos indica que fueron sometidas a temperaturas de 900-1.000 ${ }^{\circ} \mathrm{C}$ (Acevedo et al., 2012; Centeno, Williams, Little \& Speakman, 2012) Sin embargo, Cremonte (2007) detecta illita en la matriz arcillosa en las pastas de fragmentos de la Puna con inclusiones blancas no plásticas mediante el uso de SEM-EDS, lo que indicaría que la temperatura de cocción no habría superado los $700^{\circ} \mathrm{C}$. Esta diferencia en los datos muestra la necesidad de seguir indagando antes de confirmar o descartar alguna de las hipótesis.

Las pastas de los fragmentos de excavación y de las piezas de colección son macroscópicamente semejantes, aunque existen diferencias petrográficas que responden al posible uso de recursos locales. Los resultados revelaron que estas inclusiones corresponden en su mayoría a pelitas alteradas a muscovitasericita-cuarzo para las muestras de la Puna y a limonitas areniscosas, esquistos finos o corcubianitas (metamorfitas de 
contacto) para las muestras de la Quebrada de Humahuaca. Otros investigadores han registrado los mismos resultados petrográficos, es decir que, esta semejanza en las maneras de hacer las pastas podría significar una posible tradición de manufactura, que según algunos autores provendría de la Puna septentrional (Cremonte, Botto, Diaz, Viña \& Carafoglia 2007; Pérez \& Killian Galván, 2011; Sola, 2010).

\section{Consideraciones finales}

Destacamos que el avance tecnológico en las técnicas arqueométricas, la complementariedad en su aplicación y la innovación en la adaptación a materiales cerámicos arqueológicos aportaron significativamente nuevos datos e información para la resolución de las problemáticas arqueológicas analizadas en este trabajo.

En relación al caso 1, se puede considerar que las diversas líneas de evidencia utilizadas para analizar estos materiales desde un enfoque arqueométrico y tecnológico, permitieron conocer los procesos de producción y circulación del material cerámico, revelando un manejo especializado por parte de los alfareros productores. Además, los resultados avalan la hipótesis sobre su origen alóctono a la región de la Quebrada de Humahuaca y postulan una posible procedencia de producción en la región del Loa, norte de Chile, confirmando las interrelaciones sociales del área circumpuneña que establecieron los grupos aldeanos durante el inicio de sociedades productoras de alimentos en el Noroeste Argentino.

En el caso 2, de acuerdo con la perspectiva teórica adoptada y si se consideran las formas y tamaños representados en la muestra de piezas completas, junto con los acabados de superficie, los elementos del diseño, el uso de hueso molido (hidroxiapatita), las pastas con inclusiones blancas no plásticas, entre otros, responderían a un posible uso de un estilo distintivo vinculado a prácticas sociales compartidas entre las comunidades de la Quebrada de Humahuaca y las de la Puna norte y central de Jujuy, indicando que los diseños de las piezas cerámicas son una respuesta a componentes de un código visual ampliamente compartido. Algunos investigadores, sostienen que con dicho código lograban comunicar el sentido de integración vinculado al autorreconocimiento de una colectividad regional y al fortalecimiento de la cohesión interna (Nielsen, 2006a, 2006b). Es sugerente y posible que el material cerámico de este segmento hubiera tenido un consumo ceremonial relacionado con algún tipo de ritual de fortalecimiento y cohesión por parte de los grupos humanos que ocuparon los diferentes sitios de donde provienen los materiales cerámicos.

La investigación integral desarrollada consideró diferentes líneas de evidencia junto a una metodología de re-testeo y retroalimentación, que no sólo permitió analizar y caracterizar materiales referidos a una problemática arqueológica y/o antropológica, sino que contribuyó a la reflexión sobre los alcances y limitaciones de las técnicas e instrumentos empleados, cantidad, calidad y conservación de las muestras, así como modificar o incorporar técnicas de análisis para conseguir resultados compatibles con los objetivos de investigación.

Si bien, los trabajos realizados permitieron avanzar sobre los análisis de las cerámicas arqueológicas, todavía quedan estudios por realizar y muestras por sumar para generar más información. A pesar de ello, se debe destacar que el acercamiento analítico realizado con nuevas técnicas versátiles y sensibles ha producido nuevos resultados que han permitido relacionar la tecnología cerámica con las prácticas sociales de la región circumpuneña.

\section{Agradecimientos}

A la unidad de equipamiento científico MAINI de la Universidad Católica del Norte, Chile. A la empresa Soluciones Analíticas, representante de Thermo Fisher en Argentina que a través de Edgardo Gonzales y Leonardo Rossi que posibilitaron el acercamiento a nueva tecnología arqueométrica. Al Museo Arqueológico y Antropológico Dr. Eduardo Casanova de Tilcara (FFyL, UBA), y al Sr. Armando Mendoza quien facilitó el estudio y trabajo sobre las colecciones de cerámicas arqueológicas. A las colegas E. Zaburlín y M. Pérez que facilitaron muestras para parte de los estudios.

\section{Notas}

1 La Dra. María Isabel Hernández Llosas excavó y estudió la localidad arqueológica produciendo material de investigación desde los años 80 hasta la actualidad, basando sus estudios principalmente en las manifestaciones rupestres y su relación en la interacción regional.

2 La palabra puco pertenece al idioma originario quechua o quichua, y su sonido es $p$ úku, significa: plato, cuenco o escudilla. En: Diccionario de Americanismos de Salta y Jujuy, Salta (Osán de Pérez Sáez, M. F. y V. J. Pérez Sáez, 2006).

\section{Bibliografía}

Acevedo, V.J. (2011). Tecnología, uso y consumo de los conjuntos cerámicos del Alero Pintoscayoc 1, Quebrada de Humahuaca, Jujuy. (Tesis de Licenciatura). Departamento de Antropología, Facultad de Filosofía y Letras, Universidad de Buenos Aires, CABA. http://repositorio.filo.uba.ar/.

Acevedo, V.J. (2013). Protocolos de muestreo en la investigación de piezas cerámicas de colección. Mesa de Protocolos de muestreo y su incidencia en los estudios arqueológicos. En Libro de resúmenes del XVIII Congreso Nacional de Arqueología Argentina, 416-418. La Rioja: Instituto de Ciencias Humanas, Sociales y Ambientales, Universidad Nacional de La Rioja.

Acevedo, V.J. (2014). Un objeto de cerámica excepcional. Análisis de la producción tecnológica de material cerámico alóctono hallado en la Quebrada de Humahuaca, Jujuy, Argentina. En: E. Espejo, M. Eyzaguirre, E. Vargas, P. Poma, E. Huanca, E. Carvajal, C. Cárdenas, F. Maidana, L. Salazar \& A.M. Calanis (Eds.), La rebelión de los objetos. Enfoque cerámico (pp. 223-244). La Paz: MUSEF \& IFEA.

Acevedo, V.J. (2015). Ceramics at the borders of the Quebrada de Humahuaca, Jujuy, Argentina. En Program 80 Annual Meeting Society for American Archaeology, 15-19. San Francisco, CA \& USA: Published by Society for American Archaeology, Whashington DC, USA. http//www.saa.org

Acevedo, V.J. (2018). Conocimientos y procesos en la tecnología del color. Análisis arqueométrico y ensayo de materiales para el estudio de pigmentos de cerámicas arqueológicas prehispánicas del noroeste argentino. En Actas Simposio 
sobre análisis de cerámica y pigmentos, 22-28. Pontificia Universidad Católica del Perú.

Acevedo, V.J. (2019). Espacios interdisciplinarios integrales en los estudios arqueométricos. ArqueoLab -UBA: Investigar, Conservar y Difundir. En M. Bonnin, A. Lagues \& M. B. Marconetto (Eds.), Libro de resúmenes del XX Congreso Nacional de Arqueología Argentina, 1144. Córdoba: IDACOR.

Acevedo, V.J., Espinosa, A.L., López, M.A. \& Mancini, C.E. (2009). La feria de las Alasitas de Parque Avellaneda, Ciudad de Buenos Aires y sus vinculaciones con la tradición andina de miniaturas. En, Temas de patrimonio Cultural: Buenos Aires Boliviana. Migración, construcciones identitarias y memoria (pp. 249-265). Buenos Aires: Ministerio de Cultura, Gobierno de la ciudad \& Comisión para la Preservación del Patrimonio Histórico Cultural de la Ciudad Autónoma de Buenos Aires.

Acevedo, V.J. \& Herrera, N.V. (2016). Protocolos de actuación con perspectivas analíticas para muestreo, conservación y restauración en extracción e inclusión de pigmentos y reconstrucción de cerámicas del NOA. En editores, Libro de resúmenes del XIX Congreso Nacional de Arqueología Argentina, 896-902. San Miguel de Tucumán: Facultad de Ciencias Naturales e Instituto Miguel Lillo, Universidad Nacional de Tucumán.

Acevedo, V.J., Marte, F., Casarotti, M., Roa, M.A., Alpi, J. \& Espinosa, A.L. (2013). Relevamiento y análisis arqueométrico de materiales cerámicos de colecciones situadas en museos. En Actas V Congreso Nacional de Arqueometría, 45-47. Rosario: Universidad tecnológica de Rosario.

Acevedo, V.J., López, M.A., Freire, E., Halac, E.B., Polla, G. \& Reinoso, M. (2012). Estudio de pigmentos en alfarería "estilo negro sobre rojo" de quebrada de Humahuaca, Jujuy, Argentina. Boletín del Museo Chileno de Arte Precolombino - Dossier Arqueometría de pigmentos: casos arqueológicos y protocolos de investigación, 17 (2), 39-51.

Acevedo, V.J., López, M.A., Freire, E., Halac, E.B., Polla, G., Reinoso, M. \& Marte, F. (2015). Caracterización arqueométrica de pigmentos color negro de material cerámico de la quebrada de Humahuaca, Jujuy, Argentina. Chungara - edición especial del III Congreso Latinoamericano de Arqueometría, Arica 2011, 47 (2), 229-238.

Acevedo, V.J., López, M.A., Callegari, A., Halac, E B. \& Reinoso, M. (2015). Estudio tecnológico de diseños "estilo Aguada" realizados sobre fragmentos de cerámicos. En A. Piffereti \& I. Dotzal (Eds.), Arqueometría argentina. Metodologías cientificas aplicadas al estudio de los bienes culturales. Datación, caracterización, prospección y conservación (pp. 109-125). Buenos Aires: Aspha.

Acevedo, V.J, Staropoli, L., Herrera, N.V., Ciarlo, N. \& Landa, C. (2018a). ArqueoLab-UBA, un encuentro con la Ciencia Participativa. Ponencia presentada en el II Congreso de Ciencia Abierta y Ciudadana, San Martín.

Acevedo, V.J, Staropoli, L., Herrera, N.V., Ciarlo, N. \& Landa, C. (2018b). ArqueoLab-UBA, laboratorio móvil para la Ciencia Participativa. Ponencia presentada en el II Congreso de Ciencia Abierta y Ciudadana, San Martín.

Acevedo, V.J, Staropoli, L., Herrera, N.V., Ávido, D., Vítores, D. M. Soto, Gómez Coronado, M., Del Savio, P., Ciarlo, N. \& Landa, C. (2020). Proceso de patrimonialización del cañón EB 1789 del siglo XVIII en la localidad de San Antonio de Areco, Provincia de Buenos Aires. (en prensa). Cuadernos de Marte, Revista semestral del Instituto de Investigaciones Gino Germani.

Acevedo, V.J., Riera Soto, C. \& Staropoli, L. (2019). Petrografía cerámica y QEMSCAN para el estudio de la circulación de objetos y materiales cerámicos del noroeste argentino y el norte de Chile. En Actas del VI Congreso Latinoamericano de Arqueometría, 126. Bogotá: Universidad de los Andes.

Aldunate, C. \& Castro, V. (1981). Las chullpas de Toconce y su relación con el poblamiento altiplánico del Loa Superior. Periodo Tardio. Santiago: Kultrun.

Ávila, F. (2005). El estilo alfarero Yavi y su relación con la construcción de entidades culturales. Theoria, 14 (1), 85-101.

Bonnin, M. (2013). Prologo. En M.L., Endere, M.G. Chaparro \& C. Mariano (Eds.), Temas de patrimonio cultural (8-10). Tandil: Universidad del Centro de la Provincia de Buenos Aires.

Botto, I.L., Barone, V.L., Cremonte, M.B. \& Sánchez, M.A. (1998). Estudios arqueométricos de cerámicas provenientes del noroeste argentino. Información tecnológica, 9 (6), 7986.

Castro, V. \& Tarrago, M.N. (1993). Los inicios de la producción de alimentos en el cono sur de América. Revista de Arqueología Americana, 2, 329-338.

Centeno, S.A., Williams, V.I., Little, N.C. \& Speakman, R.J. (2012). Characterization of surface decorations in preHispanic and archaeological ceramics by Raman spectroscopy, FTIR, XRD and XRF. Vibrational Spectroscopy, 58, 119-124

Chaupoulie, R., Sepúlveda, M., del Solar Velarde, N. \& Wright, V. (Eds.) (2018). Arqueometría. Estudios analíticos de materiales arqueológicos. Lima: Instituto Francés de Estudios Andinos, Université Bordeaux Montaigne \& Universidad de Tarapacá.

Cremonte, M.B. (1985). Alcances y objetivos de los estudios tecnológicos en la cerámica arqueológica. Anales de Arqueología y Etnología, 38/40, 179-217.

Cremonte, M.B. (1991). Análisis de muestras cerámicas de la Quebrada de Humahuaca. Avances en Arqueología, 1, 17-42.

Cremonte, M.B. (1995). Olleras de Charabozo. Un registro de producción cerámica en la Quebrada de Humahuaca. San Salvador de Jujuy: Instituto interdisciplinario de Tilcara, Facultad de Filosofía y Letras, Universidad de Buenos Aires.

Cremonte, M.B. (2006). El estudio de la cerámica en la reconstrucción de las historias locales. El sur de la Quebrada de Humahuaca (Jujuy, Argentina) durante los Desarrollos Regionales e Incaico. Chungara, 38 (2), 239-247.

Cremonte, M.B., Botto, I.L., Díaz, A.M., Viña, R. \& Canafoglia, M.E. (2007). Vasijas Yavi-Chicha: distribución y variabilidad a través del estudio de sus pastas. En, Actas del XVI 
Congreso Nacional de Arqueología Argentina, 145-147. San Salvador de Jujuy: Facultad de Ciencias Sociales y Humanas, Universidad Nacional de Jujuy.

Contreras Torres L. F., (2015). Caracterización mineralógica del proceso metalúrgico y su impacto en la producción de concentrados de $\mathrm{Cu}$ y $\mathrm{Mo}$ en CMDIC. Memoria para optar al título de Geólogo.Universidad de Chile, Facultad de Ciencias Físicas y Matemáticas departamento de geología. Chile. MS.

Deambrosis, M.S. \& de Lorenzi M.E. (1975). Definición de nuevos tipos cerámicos (análisis de materiales procedentes de Peña Colorada, Provincia de Jujuy). En, Actas y trabajos del I Congreso Nacional de Arqueología Argentina, 451-461. Buenos Aires: Universidad de Buenos Aires.

De la Fuente, G.A., Kristcautzky, N. \& Toselli, G. (2007). Pigmentos, engobes y alfareros: Una aproximación arqueométrica (MEB-EDS) al estudio de pigmentos en cerámicas arqueológicas del noroeste argentino: el caso del estilo cerámico "Aguada Portezuelo" del valle de Catamarca. En B. Cremonte \& N. Ratto (Eds.), Cerámicas arqueológicas. Perspectivas arqueométricas para su análisis e interpretación (pp. 39-47). San Salvador de Jujuy: Facultad de Ciencias Sociales y Humanas, Universidad Nacional de Jujuy.

De la Fuente, G.A. \& Martínez, J.M. (2008). Estudiando pinturas en cerámicas "Aguada Portezuelo" (ca. 600-900 AD) del noroeste argentino: nuevos aportes a través de una aproximación arqueométrica por microespectroscopia raman (MSR). Intersecciones en Antropología, 9, 173-186.

del Solar Velarde, N., Cantin, N. \& Chaupoulie, R. (2018). Cerámica. En: R. Chapoulie, M. Sepúlveda, N. del Solar Velarde \& V. Wright (Eds.), Arqueometría. Estudios analíticos en materiales arqueológicos (pp. 415-434). Lima: Instituto Francés de Estudios Andinos \& UMIFRE MEAE/ CNRS.

Druc, I. (2005). Producción cerámica y Etnoarqueología en Conchucos, Ancash, Perú. Bulletin de l'Institut français d'études andines, 34 (3), 480-485.

Druc, I. (2014). Pastas cerámicas en lupa digital (componentes, textura y tecnología). Wisconsin: Deep University Press.

Endere, M. L; Chaparro, M.G. \& Mariano, C. (2013). Introducción. En M.L. Endere, Chaparro, M.G \& C. Mariano (Eds.), Temas de patrimonio cultural (14-29). Tandil: Universidad del Centro de la Provincia de Buenos Aires.

Freire, E., Acevedo, V.J., Halac, E.B., Polla, G., López M. \& Reinoso, M. (2015). X-ray diffraction and raman spectroscopy study of white decorations on tricolored ceramics from Northwestern Argentina. Spectrochimica Acta Part A: Molecular and Biomolecular Spectroscopy, 157, 182-185.

Guirao, M. (2015). Arqueometría. Cambios y tendencias actuales. New York: Springer Science + Busines Media, LLC.

Herrera, N.V. \& Acevedo, V.J. (2019). La conservación de pigmentos arqueológicos y la generación de base de datos. Boletín de Arqueología de la Pontifica Universidad Católica del Perú, 27, 103-115.
Hernández Llosas, M.I. (1991). Modelo procesual acerca del sistema cultural Humahuaca tardío y sus modificaciones ante el invasor europeo. En M.M. Podestá, M.I. Hernández Llosas \& Renard de Coquet (Eds.), Arte rupestre en la Arqueología contemporánea (pp. 53-65). Buenos Aires: eudeba.

Hernández Llosas, M.I. (1998). Pintoscayoc: arqueología de las quebradas altas en Humahuaca. Tesis para optar al título de doctor en arqueología. Facultad de Filosofía y Letras Universidad de Buenos Aires. MS.

Hernández Llosas, M.I. (2000). "Quebradas Altas de Humahuaca a través del tiempo: El caso Pintoscayoc". Estudios sociales del NOA, año $3, \mathrm{~N}^{\circ}$ 2. Instituto Interdisciplinario de Tilcara, Universidad de Buenos Aires, FFyL, Jujuy.

Hernández Llosas, M.I. (2006). Inkas y españoles a la conquista simbólica del territorio de Humahuaca: sitios, motivos rupestres y apropiación cultural del paisaje. Boletín del Museo de Arte Chileno Precolombino, 11 (2), 9-34

Leoni, J.B \& Hernández Llosas, M.I. (2015). La ocupación humana de las nacientes de la quebrada de Humahuaca en el rango 3000-1000 A.P.: evidencias arqueológicas, discusión y perspectivas. En M.A. Korstanje, M. Lazzari, M. Basile, F. Bugliani, V. Lema, L. Pereyra Domingorena \& M. Quesada (Eds.), Crónicas materiales precolombinos: arqueología de los primeros poblados del noroeste argentino (151-182). Ciudad Autónoma de Buenos Aires: Sociedad Argentina de Antropología.

López, M.A. (1999-2001). Los núcleos de cocción en las pastas cerámicas arqueológicas, indicadores y variables relacionados con algunos aspectos de la secuencia de producción. Xama, 12-14, 133-149.

López, M.A. (2004). Tecnología cerámica en la Huerta, Quebrada de Humahuaca, Provincia de Jujuy. (Tesis de doctorado). Departamento de Antropología, Facultad de Filosofía y Letras, Universidad de Buenos Aires.

Marte, F., Acevedo, V.J., Mastrangelo, N. (2012). Técnicas arqueométricas combinadas aplicadas al análisis de diseños de alfarería "tricolor" de Quebrada de Humahuaca, Jujuy, Argentina. Boletín del Museo Chileno de Arte Precolombino, 17 (2), 53-64.

Martínez, J.L. (1990). Interetnicidad y complementariedad en el altiplano meridional: el caso atacameño. Revista Andes, 1 (1), 11-30.

Nielsen, A.E. (1988). Un modelo de sistema de asentamiento prehispánico en los valles orientales de Humahuaca. Comenchingonia, 5 (6), 129-155.

Nielsen, A.E. (1997). Tiempo y cultura material en la quebrada de Humahuaca 700-1650 d.C. San Salvador de Jujuy: Instituto Interdisciplinario Tilcara, Facultad de Filosofía y Letras, Universidad de Buenos Aires.

Nielsen, A.E. (2001). Evolución social en Quebrada de Humahuaca (AD 700-1536). En: E. Berberián \& A. Nielsen (Eds.), Historia Argentina Prehispánica Vol. 1 (pp. 171-264). Córdoba: Editorial Brujas.

Nielsen, A.E. (2006a). Pobres jefes: aspectos corporativos en las formaciones sociales pre-incaicas de los Andes 
circumpunenos. En C. Gnecco \& C. Langebaek (Eds.), Contra el pensamiento tipológico: reflexiones teóricas actuales sobre complejidad social (pp. 121-150). Bogotá: Universidad de los Andes.

Nielsen, A.E. (2006b). Plazas para los antepasados: descentralización y poder corporativo en las formaciones políticas preincaicas de los Andes circumpuneños. Estudios Atacameños, 31, 63-89.

Nielsen, A.E. (2010 [2007]). Celebrando con los antepasados. Arqueología del espacio público en Los Amarillos (quebrada de Humahuaca, Jujuy, Argentina). Buenos Aires: Mallku Ediciones.

Nielsen A.E. (2019). Las primeras comunidades sedentarias del noroeste argentino: entre la evolución y la historia. Intersecciones en Antropología, 18, 131-133.

Olivera, D.E. (2001). Sociedades agropastoriles tempranas: el Formativo Inferior del noroeste argentino. En E. Berberian \& A. Nielsen (Eds.), Historia Argentina Prehispánica (Vol. 1 pp. 83-125). Córdoba: Editorial Brujas.

Olivera, D. E. \& Yacobaccio, H.D. (1999). Estudios de paleodieta en poblaciones humanas de los andes del sur a través de isótopos estables. En Actas del XII Congreso Nacional de Arqueología Argentina, 190-201. Córdoba: editorial Brujas.

Osán de Pérez Sáez, M. F. y V. J. Pérez Sáez (2006). Diccionario de americanismos en Salta y Jujuy (República Argentina). Editorial La Muralla, Arco Libros S.A. Madrid, España. ISBN: 978-84-7635-631-9. Palma, J.R. (1998). Curacas y señores. Una visión de la sociedad política prehispánica en la quebrada de Humahuaca. San Salvador de Jujuy: Instituto Interdisciplinario Tilcara, Facultad de Filosofía y Letras, Universidad de Buenos Aires.

Palamarczuk, V., Fernández de Rapp, M.E. \& Lascalea, G.E. (2007). Aproximaciones a la caracterización del material blanco decorativo de la cerámica Famabalasto negro gravado. En M.B. Cremonte \& N. Ratto (Eds.), Cerámicas arqueológicas. Perspectivas arqueométricas para su análisis e interpretación (pp. 27-37). San Miguel de Jujuy: Universidad Nacional de Jujuy.

Pérez, M. \& Killian Galván, V. (2011). Doncellas (Puna septentrional, Jujuy, Argentina): nuevos enfoques a partir del estudio cerámico y del análisis paleodietario. Estudios Atacameños, 42, 79-100.

Riera Soto, C. (2019). Estudio petrográfico de las cerámicas formativas en la cuenca del río Vilama y oasis de San Pedro de Atacama (norte de Chile): materias primas en circulación. (Tesis Magister). Universidad Católica del Norte, Antofagasta.

Riera-Soto, C., Uribe, M., Menzies, A. \& Barraza, M. (2018). Avances en petrografía automatizada: cerámicas tempranas de Guatacondo, norte de Chile (900 AC-200 DC). Boletín de Arqueología de la Pontifica Universidad Católica del Perú (PUCP), 24, 141-157.

Rivolta, M.C. (1997). Revisión crítica de la obra de Bennett y colaboradores sobre la definición y asignación cronológica de algunos estilos cerámicos de la quebrada de Humahuaca.
Avances en Arqueología, 3, 131-146.

Rye, O. (1981). Pottery technology: principles and reconstruction. Washington: Taraxacun Inc.

Sinclaire, C.A. (2004). Prehistoria del periodo formativo en la cuenca del rio Salado (región del Loa superior. Chungara, $36,619-639$.

Sola, P. (2010). Tiestos trazadores de cerámica exótica en sitios tardíos de los alrededores de Susques (Jujuy, Puna, Argentina). Intersecciones en Antropología, 12, 177-194.

Tarragó, M.N. (2000). Chacras y pukaras, desarrollos sociales tardíos. En: Nueva Historia Argentina. Los pueblos originarios y la conquista (Vol. 1, pp. 259-300). Barcelona: Sudamericana.

Zaburlín, M.A. (2012). La cerámica tricolor de la Puna jujeña: variabilidad de los motivos con vírgulas y puntos blancos. Arqueología, 18, 131-152. 
